\title{
Structural features of reconstituted cuticular wax films upon interaction with nonionic surfactant C12E6
}

DOI:

10.1021/acs.langmuir.8b00143

\section{Document Version}

Accepted author manuscript

Link to publication record in Manchester Research Explorer

\section{Citation for published version (APA):}

Lu, J., Pambou, E., Hu, X., Li, Z., Campana, M., Webster, J. P. R., Bell, G., Hughes, A., \& Li, P. (2018). Structural features of reconstituted cuticular wax films upon interaction with nonionic surfactant C12E6. Langmuir, 34, 33953404. https://doi.org/10.1021/acs.langmuir.8b00143

\section{Published in:}

Langmuir

\section{Citing this paper}

Please note that where the full-text provided on Manchester Research Explorer is the Author Accepted Manuscript or Proof version this may differ from the final Published version. If citing, it is advised that you check and use the publisher's definitive version.

\section{General rights}

Copyright and moral rights for the publications made accessible in the Research Explorer are retained by the authors and/or other copyright owners and it is a condition of accessing publications that users recognise and abide by the legal requirements associated with these rights.

\section{Takedown policy}

If you believe that this document breaches copyright please refer to the University of Manchester's Takedown Procedures [http://man.ac.uk/04Y6Bo] or contact uml.scholarlycommunications@manchester.ac.uk providing relevant details, so we can investigate your claim.

\section{OPEN ACCESS}


Langmuir. 2018 Mar 20;34(11):3395-3404. doi: 10.1021/acs.langmuir.8b00143. Epub 2018 Mar 5.

Structural features of reconstituted cuticular wax films upon interaction with nonionic surfactant $\mathrm{C}_{12} \mathrm{E}_{6}$

Elias Pambou ${ }^{a}$, Xuzhi Hu ${ }^{a}$, Zongyi Li $^{a}$, Mario Campana ${ }^{b}$,Arwel Hughes ${ }^{b}$, Peixun Li $i^{b}$, John R.P. Webster ${ }^{b}$, Gordon Bell, Jian R. $\mathrm{Lu}^{a^{*}}$

*E-mail: j.lu@manchester.ac.uk. Tel: (+44)-161-200-3926.

a Biological Physics Group, School of Physics and Astronomy, University of Manchester, Oxford Road, Manchester, M13 9PL, UK.

${ }^{\mathrm{b}}$ STFC ISIS Facility, Rutherford Appleton Laboratory, Didcot OX11 0QX, UK.

${ }^{\mathrm{c}}$ Syngenta, Jealott's Hill International Research Centre, Bracknell, Berkshire, RG42 6EY, UK.

Keywords: Wheat waxes, plant waxes, cuticular films, neutron reflection, spectroscopic ellipsometry, nonionic surfactant 


\begin{abstract}
The interaction of nonionic surfactant hexaethylene glycol monododecyl ether $\left(\mathrm{C}_{12} \mathrm{E}_{6}\right)$ with a reconstituted cuticular wheat wax film has been investigated by spectroscopic ellipsometry (SE) and neutron reflection (NR) to help understand the role of the leaf wax barrier during pesticide uptake, focusing on the mimicry of the actions adjuvants impose on the physical integrity and transport of the cuticular wax films against surfactant concentration. As $\mathrm{C}_{12} \mathrm{E}_{6}$ concentration was increased up to the critical micelle concentration $(\mathrm{CMC}=0.067 \mathrm{mM})$, an increasing amount of surfactant mass was deposited onto the wax film. Alongside surface adsorption, $\mathrm{C}_{12} \mathrm{E}_{6}$ was also observed to penetrate the wax film, evident from the NR measurements using fully protonated and chain-deuterated surfactants. Furthermore, surfactant action upon the model wax film was found to be physically reversible below the $\mathrm{CMC}$ as water rinsing could readily remove the adsorbed surfactant, leaving the wax film in its original state. Above the CMC, the detergency action of the surfactant became dominant, and a significant proportion of the wax film removed, causing structural damage. The results thus reveal that both water and $\mathrm{C}_{12} \mathrm{E}_{6}$ could easily penetrate the wax film throughout the concentration range measured, indicating a clear pathway for the transport of active ingredients whilst the removal of the wax components above CMC must have enhanced the transport process. As the partial removal of the wax film could also expose the underlying cutaneous substrate to the environment and undermine the plant's health, this study has a broad implication to the roles of surfactants in crop care.
\end{abstract}




\section{Introduction}

Plant species have evolved over millions of years to withstand different living environments such as extreme droughts and temperatures. Survival in these conditions is at least in part attributed to the role of the plant cuticular waxes that make up the outermost surfaces of crops by forming a thin skin with thicknesses ranging from $10 \mathrm{~nm}$ to $10 \mu \mathrm{m} .{ }^{1-4}$ The waxy skin layer covers and is well impregnated into the underlying cutaneous lining comprised of a complex structure of polysaccharides and cutin. They together provide a barrier between the external environment and underlying tissue within the plant. ${ }^{1,4,5}$ Along with protecting the plant from pests and pathogens, the waxy film plays an important role in moderating the transport and uptake of water, nutrients or agrichemicals through the plant's skin and into the cells. ${ }^{3,6}$ It has previously been demonstrated that the removal of cuticular waxes from crops can increase water permeability by up to four orders of magnitude, highlighting the important role of the waxy films in plant maintenance. $^{4,7,8}$

A key aim in current adjuvant science is to characterize the structure and transport properties of cuticular wax films in crops in order to understand how the active ingredients in pesticide formulations penetrate through the leaf surface. The structure and chemical composition of cuticular waxes can differ between different species. Even from the same species, their morphological appearance and physical properties can vary, depending on their age, growing conditions and environments. ${ }^{9,10}$ Components bearing straight aliphatic chains make up a large part of cuticular waxes, but variations in chain length distribution and functional group can lead to the formation of waxy films with different thickness, crystallinity, hydrophobicity and morphology, resulting in different wax film permeability. The application of pesticides may modify or even compromise these properties, leading to drastic changes to wax transport behaviour $^{1-4,7,8,11-14}$, but the exact molecular processes have not been well elucidated. 
Surfactants are an important ingredient of pesticidal formulations and are responsible for the solubilization and delivery of active ingredients to the plant or crop. Commercial agrichemical formulations are generally comprised of a complex combination of polydisperse surfactants and solvents with a wide range of physical and chemical properties which are exploited in the formulation of efficacious crop care products.

Studies such as those carried out by Burghardt and Riederer, amongst others, have previously investigated the action of representative nonionic surfactants upon cuticular waxes using techniques such as capillary gas chromatography (GC) and nuclear magnetic resonance (NMR) to monitor the permeability and diffusion of surfactants into cuticular waxes. ${ }^{15-19}$ Nonionic surfactants found in agrochemical formulations such as the alcohol ethoxylate type have been shown to influence the penetration and transfer of water and nutrients across extracted cuticular waxes by mediating the hydrophobic plant wax interface. The interaction efficacy varies with surfactant's amphiphilic properties, simply represented by its hydrophilic-lipophilic balance (HLB). ${ }^{15,19-21}$ Alcohol ethoxylates can increase water permeability in reconstituted Pyrus communis L. (pear) and Citrus aurantium L. (Seville oranges) bulk waxes by 150 and 15 times, respectively, whilst the mobility of active ingredients through the waxes could be directly correlated with surfactant concentration. ${ }^{15}$ While the detergency and amphiphilic properties of surfactant micelles are generally well understood, their influences with regards to crop care and their potential compromises on the ultrathin wax film structure on the plant surface have not been well studied at the molecular level.

Whilst microscopic imaging has been well established in plant research, it remains difficult to gain reliable information about wax film changes on leaf surfaces at the molecular level. This is particularly challenging when surfactants are involved. In a previous study, we have reconstituted representative ultrathin cuticular wax films using wheat waxes extracted by either chloroform or supercritical $\mathrm{CO}_{2}{ }^{22}$ These model wax films facilitated direct measurements from neutron reflection (NR) alongside imaging techniques including scanning electron microscopy (SEM) and 
atomic force microscopy (AFM) and further supported by ellipsometric measurements. These studies showed that the reconstituted cuticular wax films consist of an underlying film structure with crystalline extrusions diffusely scattered upon the outer surface, broadly consistent with the main structural feature of the natural cuticular wax films of wheat leaves. The underlying film has a porous sponge-like network that allows water to easily penetrate the wax barrier, a structural feature that may help explain the regulatory effects of the cuticular wax film to water from plants. ${ }^{4,22}$ This structural feature was also in agreement with the outcome of SEM studies conducted by Koch et al. showing a perforated wax film structure. ${ }^{23}$ In several studies previously reported, plant waxes were treated as bulk materials and the water diffusion coefficients were of the order of $\sim 10^{-18}$ to $10^{-16} \mathrm{~m}^{2} \mathrm{~s}^{-1} \cdot{ }^{15,20}$ These values are significantly lower than what are expected in real cuticular wax films. We speculate that structural features such as porosity and defects as often observed in wax films must play a crucial role in regulating transport through the plant surface barriers. ${ }^{15,20}$

Following the previous success in the development of reconstituted wax films ${ }^{22}$, this work aims to continue the theme of neutron reflection-led studies by examining how surfactants interact with the wax films, thereby providing useful indications of the role played by surfactants. Whilst NR provides reliable information about the structure and composition of the interface before and after surfactant binding, spectroscopic ellipsometry (SE) offers a real time, in-situ observation of the dynamic process. Agri-sprays use surfactant mixtures mainly containing nonionics. As this is one of our first studies to examine how surfactants interact with wax films it focuses on exploring the technical feasibility. The monodisperse nonionic surfactant hexaethylene glycol monododecyl ether $\left(\mathrm{C}_{12} \mathrm{E}_{6}\right)$ was chosen to highlight the main structural features. The combination of NR and SE can yield additional information to validate the changes to the mass and density of the cuticular wax film as it interacts with the model surfactant. The successful fitting and interpretation of the data using both techniques could help us understand the actions of the surfactant on plant wax surfaces and its impact on the transport properties. 


\section{Experimental Section}

\section{Wax extraction - supercritical $\mathrm{CO}_{2}$ wax extraction from field grown straws}

Reconstituted cuticular wax films were prepared from waxes extracted from field grown Triticum aestivum L. straws of Sabre wheat variety. The straws were harvested as bulk agri-residues on a large scale and then milled into particulates of $0.5-5 \mathrm{~mm}$. The cuticular wheat waxes were extracted using supercritical $\mathrm{CO}_{2}$ from a pilot plant developed and the full details are given by Deswarte et $a l .{ }^{24}$ The supercritical $\mathrm{CO}_{2}$ wax extraction was undertaken at the pressure of 100 bar and temperature of $40{ }^{\circ} \mathrm{C}$ for $100 \mathrm{~min}$ and at a constant flow rate of $5 \mathrm{~kg} / \mathrm{hr}$ to give a wax yield $>0.4 \% \mathrm{w} / \mathrm{w}$ of the total wheat straws.

The main technical advantage of this method over more traditional approaches is the selective extraction on a large scale. The fraction of unwanted compounds can be minimized by tuning the reaction time, pressure and temperature and therefore the $\mathrm{CO}_{2}$ solvent strength. Thus, a maximum yield of cuticular waxes can be isolated without unwanted co-extractives such as polar lipids or sugars. Additionally, no solvent residue is left behind and no further purification is required.

\section{Sample preparation and thin film coating}

Sample preparation procedures used for SE and NR measurements were the same as those previously described by Pambou et al. ${ }^{22}$ Reconstituted wax films were spin-coated onto an optically flat silicon ( $\mathrm{Si}$ ) substrate to facilitate the measurements. Prior to coating, the polished $\mathrm{Si}$ block surfaces undergo Piranha cleaning with a $\mathrm{H}_{2} \mathrm{SO}_{4}: \mathrm{H}_{2} \mathrm{O}_{2}$ ratio of $3: 1$ at $90{ }^{\circ} \mathrm{C}$ for $10 \mathrm{~s}$ before being meticulously washed using lint-free tissue soaked with 5\% Decon-90 solution (Decon Laboratories Ltd.) and rinsed repeatedly with copious amounts of de-ionized water (resistivity at $18 \mathrm{M} \Omega \mathrm{cm}$, Purelab UHQ, Vivendi Water Systems Ltd.) and dried under nitrogen gas. After cleaning, the native oxide layer $\left(\mathrm{SiO}_{2}\right)$ present on the $\mathrm{Si}$ surface was measured using SE. Using this cleaning method, the $\mathrm{SiO}_{2}$ layers had a reproducible thickness of 12-15 $\mathrm{A}$.

Before deposition onto the Si substrate, the extracted wax was dissolved in chloroform (> 99\%, Sigma Aldrich Co. Ltd) at a concentration of $0.05 \% \mathrm{w} / \mathrm{w}$ and placed in an ultrasonic bath for 15 
min to assist dissolution. For NR measurements, reconstituted wax films were then produced by depositing $1 \mathrm{ml}$ of wax solution onto the Si block $(50 \mathrm{~mm} \times 60 \mathrm{~mm} \times 12 \mathrm{~mm})$, held in place with vacuum under nitrogen purge conditions immediately prior to spin-coating (Laurell Technologies, MODEL WS-650MZ-23NPP). The process was programmed to run for $20 \mathrm{~s}$ at $3000 \mathrm{rpm}$, with an initial acceleration of $1000 \mathrm{rpm}$ for $3 \mathrm{~s}$. This coating procedure for forming reconstituted wax films was discussed in the previous study and was found to generate reproducible uniform films within the thickness range of cuticular wax films found in cereal crops. ${ }^{22}$ For SE measurements, Si wafers $(2 \mathrm{~cm} \times 2 \mathrm{~cm})$ were spin coated in the fashion similar to the Si blocks used for NR, with $200 \mu$ of solution deposited onto the surface prior to coating. Surfactant solutions were prepared at $0.1,0.5,1.0,5.0$ and $10.0 \mathrm{CMC}$ of $\mathrm{C}_{12} \mathrm{E}_{6}\left(\mathrm{hC}_{12} \mathrm{E}_{6}, \mathrm{CMC}=\right.$ $0.067 \mathrm{mM}^{25}, \geq 98.0 \%$, Sigma Aldrich) in deionized water at $20-22{ }^{\circ} \mathrm{C}$. Solutions were placed in an ultrasonic bath for 15 min to assist dissolution. The chain-deuterated surfactant $\left(\mathrm{dC}_{12} \mathrm{E}_{6}\right)$ was prepared by the ISIS Deuteration Laboratory, at RAL, STFC by the standard Williamson synthesis with full details on synthesis and purification given by Lu et al. ${ }^{26}$

\section{Spectroscopic ellipsometry (SE)}

All the SE measurements were made at a fixed incidence angle of $70^{\circ}$ over a wavelength range of 200 to $1000 \mathrm{~nm}$ using the instrument from J.A. Woollam Co. Inc. The use of spectroscopic ellipsometry as opposed to the single wavelength one greatly constrains the data analysis and provides more reliable information about the sample being measured. Measurements of the dynamic changes to the reconstituted wheat wax film upon its exposure to solutions of $\mathrm{C}_{12} \mathrm{E}_{6}$ were undertaken at the solid/liquid interface. Prior to exposing the surfactant solutions to the wax film, deionized water was allowed to flow over the film surface for $30 \mathrm{~min}$ to obtain the reference SE measurements. After characterizing the reconstituted wax film measured under water, $\mathrm{C}_{12} \mathrm{E}_{6}$ surfactant solutions (each at $2 \mathrm{ml}$ ) were injected through the inlet tube of the purposely-built SE liquid-cell system (500 $\mu 1$ Variable Temperature LiquidCell ${ }^{\mathrm{TM}}$, J.A. Woollam Co. Inc) and onto the wax coated Si surface in order of increasing concentration. Flow was controlled at a rate of 5 
$\mathrm{ml} / \mathrm{min}$, consistent with NR. Dynamic SE scans of the deposited solutions were carried out for 10 min at each of the surfactant concentrations measured, followed by injection of $2 \mathrm{ml}$ deionized water into the liquid cell to rinse away loosely adsorbed surfactant. For each rinse cycle lasting 10 min the wax film was measured again to determine the effects of surfactant removal upon the integrity of the wax film. In total, 11 measurements were carried out to describe the effects of surfactant adsorption and removal from the wax film. While full adsorption of $\mathrm{C}_{12} \mathrm{E}_{6}$ onto reconstituted wax films was observed to occur over the order of seconds, only measurements from the final $5 \mathrm{~min}$ of each of the 10 min scans was used to calculate the mean film thickness and refractive index to ensure that the surfactant was fully equilibrated upon exposure to the wax film surface. A scan rate of 20 scans/s was used for the dynamic liquid cell investigation.

From SE measurements of layer thickness, $\tau$ and refractive index, $n$, both the mass per unit area, $m$, and the dry density, $\rho_{L}$ of the measured wax film with and without adsorbed surfactant can be calculated using the De Feijter equation ${ }^{27}$ :

$$
\begin{gathered}
\rho_{L}=\rho_{m}\left(n_{L}-n_{s}\right) /\left(n_{m}-n_{s}\right) \\
m=\tau_{L} \rho_{L}
\end{gathered}
$$

where $\tau_{L}$ is the thickness of the measured layer, $\rho_{L}$ is its layer density, $\rho_{m}$ is the material bulk density $\left(0.934 \mathrm{~g} / \mathrm{cm}^{3}\right.$ for reconstituted wheat wax, measured by suspension in solution), $n_{s}$ is the solvent refractive index, $n_{L}$ is the measured layer refractive index and $n_{\mathrm{m}}$ is the refractive index of the measured material. For reconstituted wheat wax extracted by supercritical $\mathrm{CO}_{2}$ this was calculated to be $1.478 \pm 0.005$ (at the sodium D-line, $589 \mathrm{~nm}$ ). The refractive index-wavelength relationship was determined from refractometry measurements of the wheat wax film using various spectral sources and using Cauchy's empirical relationship for a transparent material, with full details of the method used being described in the Electronic Supplementary Material.

\section{Neutron reflection (NR)}

Theory In specular neutron reflection, a highly collimated beam of neutrons is elastically scattered off an interfacial material deposited on an optically flat substrate at an grazing incidence 
angle into a detector. ${ }^{28}$ Specular reflectivity is defined as the ratio of reflected intensity over incident intensity. The intensity of the reflected radiation is measured as a function of momentum transfer, $Q$, perpendicular to the reflecting surface, where $Q=(4 \pi \sin \theta) / \lambda$, with $\lambda$ denoting the neutron wavelength and $\theta$ the incident angle.

The measured specular reflectivity profile provides information of the interfacial material's nanoscale structure, density and composition. Analogous to the reflection of light, the specular reflection of neutrons is governed by the neutron refractive index, $n$, of scattering nuclei and is related to the neutron's wavelength (for non-absorbent materials) by $n(z)=1-\left[\lambda^{2} \rho(z)\right] / 2 \pi$, where $\rho(z)$ denotes the scattering length density $\left(\operatorname{SLD}, \AA^{-2}\right.$ ) of the material at a distance, $z$ along the normal to the interface. The SLD of a material is an additive quantity dependent on the coherent neutron scattering length, $b$, and volume fraction of each isotopic compound which makes up the material in question. ${ }^{29,30}$

The neutron SLD of a material can be determined if its chemical composition is known. Several studies have determined the chemical composition of cuticular waxes using techniques such as NMR spectrometry, mass spectroscopy (MS), differential scanning calorimetry (DSC) and gas chromatography. ${ }^{12,31}$ Wheat waxes consist primarily of n-alkanols $\left(\mathrm{C}_{22-30}\right)$, esters $\left(\mathrm{C}_{44}, 10 \mathrm{~m} \%\right)$ and alkanes $\left(\mathrm{C}_{27-33}\right)$, with the $\mathrm{n}$-alkanol chain $\mathrm{C}_{28}$ being most prominent $(66 \mathrm{~m} \%){ }^{23,24}$ The SLD of the wheat wax films was determined by assuming that it was primarily made up of $\mathrm{C}_{28}$ alcohol and $\mathrm{C}_{44}$ ester giving an estimated SLD value of $-0.3 \times 10^{-6} \AA^{-2}$. Minor components such as $\mathrm{C}_{26,30}$ alcohols, fatty acids and alkanes of different chain lengths all have similar SLDs. Because SLDs vary between elemental isotopes, a technique named isotopic substitution, or contrast variation, can be used to change the scattering contribution of a measured material or its constituent without significantly altering its structure and chemical composition. ${ }^{28,30,32,33}$ Isotopic substitution is often used to change the measured material's SLD, resulting in different reflectivity profiles. For the measurement of cuticular wheat waxes in water, $\mathrm{D}_{2} \mathrm{O}\left(6.35 \times 10^{-6} \AA^{-2}\right)$, as opposed to $\mathrm{H}_{2} \mathrm{O}$ ($0.56 \times 10^{-6} \AA^{-2}$ ), is used as the solvent due to its high scattering contrast to the wax film, with the 
large contrast increasing the film's scattering contribution. Its mixing into the pores or channels within the wax film leads to the increase of the SLD of the measured film. Thus, the use of $\mathrm{D}_{2} \mathrm{O}$ can help highlight the wax film. Table S1 in the Electronic Supplementary Material gives a list of scattering lengths and SLDs for materials used in this study.

Method Specular solid/liquid NR measurements were carried out using the SURF time-of-flight reflectometer at the ISIS Neutron and Muon Facility, Rutherford Appleton Laboratory (RAL), Didcot, UK. ${ }^{28,34}$ Measurements were made using a variable angle sample stage at $0.30^{\circ}, 0.70^{\circ}$ and $1.50^{\circ}$ to the incoming beam to provide a NR profile covering a Q-range (wave vector range) of 0.010-0.40 $\AA^{-1}$. Transmission scans through air and the silicon block were undertaken prior to the measurements to normalise the reflectivity signal. The background from the incoherent scattering of neutrons was taken into account when analyzing the normalized data and a flat background of 6 to $8 \times 10^{-6}$ was applied to all model fits. As it typically takes about $1 \mathrm{hr}$ to compete a reflectivity profile, the NR represented the average profile over the measurement period. However, as shown from SE measurements, the system could reach equilibration within seconds of water penetration, swelling and surfactant adsorption. All measurements were carried out at the ambient temperature of $293-295 \mathrm{~K}$.

A purpose-built liquid cell comprised of a Perspex trough (1.5 ml volume), with connections for liquid flow clamped to the silicon block by means of a steel assembly was used to provide a sample environment and facilitate the solid/liquid interface measurements by NR. Flow was controlled manually at a measured rate of $5 \mathrm{ml} / \mathrm{min}$ to ensure that the wax film was unaffected by the shear forces associated with the flow.

Solid/liquid NR measurements of the model reconstituted wax film were first carried out under $\mathrm{D}_{2} \mathrm{O}$ to establish the wax film structure (control), and subsequently with $\mathrm{C}_{12} \mathrm{E}_{6}$ at concentrations of $0.05,0.2,0.5,1$ and $5 \mathrm{CMC}$ in $\mathrm{D}_{2} \mathrm{O}(\mathrm{CMC}=0.067 \mathrm{mM})$, with water rinsing carried out between each surfactant injection. Two sets of measurements were undertaken with $\mathrm{C}_{12} \mathrm{E}_{6}$; one set using fully-protonated $\mathrm{hC}_{12} \mathrm{E}_{6}$ and one using chain-deuterated $\mathrm{dC}_{12} \mathrm{E}_{6}$. 
Data Analysis Neutron reflectivity profiles were evaluated using RasCal (A. Hughes, ISIS Spallation Neutron Source, Rutherford Appleton Laboratory) which employs an Abeles optical matrix formalism to approximate the neutron density profile of the wax film with and without surfactant adsorption. ${ }^{35-38}$ The reflectivity profile which represents the structural distribution of an interfacial material is described by the Abeles layer model through a discrete series of homogeneous slabs each characterized by their SLD and thickness. ${ }^{28,30}$

In this study, the general solution to the optical matrix used to describe any standard stratified layer $^{22,23}$ was modified to more accurately describe the observed interfacial roughness and density variations of the reconstituted cuticular wax films. It has been shown that the material's volume fraction and SLD distribution profiles could be adequately described using a 2-layer model based on the error function model developed by Hughes. ${ }^{22,38}$ The 2-layer Hughes error function model provides a good description of the underlying cuticular film and crystalline surface extrusion region as observed in the wheat wax film. Each layer, $n$, is described in terms of its thickness, $\tau_{n}$, a Gaussian error (roughness) parameter, $\sigma_{n}$, which defines the shape of the modelled layer's density distribution, and $\varphi_{n}$, which is a scale factor term denoting the coverage of the modelled layer by assuming a uniform slab with a defined SLD. $\tau_{n}, \sigma_{n}$ and $\varphi_{n}$ are fitted parameters which can be modified in response to changes in layer shape and structure, as observed for the wax film in response to surfactant adsorption or penetration and water rinsing. Further details of this model and definitions of the parameters used are described in the previous study of the reconstituted wax films ${ }^{22}$, and in the Electronic Supplementary Material.

A least-squares minimization (Nelder-Mead Simplex) was used to compare the calculated reflectivity profiles to the experimental data, with the best fitted parameters obtained. In all cases, within error, the simplest possible model which satisfactorily described the data was selected. The standard errors associated with each measurement were estimated using a bootstrap resampling algorithm built into the RasCal fitting software. ${ }^{38}$ The $\mathrm{SiO}_{2}$ layer was measured to have a fixed thickness and decay parameter $\tau, \sigma$, of $15 \AA$ and $2 \AA$, respectively. The $\mathrm{SiO}_{2}$ 
parameters were fixed for all NR measurements. For all NR measurements from the underlying wax films, the errors associated with the model fitting parameters for each layer, $\tau_{n}, \sigma_{n}$, and $\varphi_{n}$ were always found to be within $1.5 \%$ of the best fitted values. For the more diffuse surface extrusion regions, errors increased to $10-15 \%$ of the best fitted values as sensitivity decreased. More details of the model used and the best parameters are also given in the Electronic Supplementary Material.

\section{Results and Discussion}

\section{Surfactant binding measured from SE}

The dynamic interaction between the nonionic surfactant $\mathrm{C}_{12} \mathrm{E}_{6}$ and reconstituted model wheat wax film was monitored by SE at the solid/liquid interface to examine how an increase in the concentration of $\mathrm{C}_{12} \mathrm{E}_{6}$ affects its binding to the wax film across the CMC range. Changes in the elliptically polarized light as it is reflected from a supported interfacial film are quantified from the variations in its amplitude, $\Psi$, and phase, $\Delta$, which are mathematically modelled over the measured wavelength range to determine film thickness and refractive index. The change in the polarisation state of the light is given by:

$$
P=\tan (\Psi) e^{i \Delta}
$$

where $P$ is the complex reflectance ratio termed ellipticity of light describing the fraction of light reflected and transmitted at an interface between media of differing refractive indices ${ }^{39} . \Psi$ and $\Delta$ denote the amplitude ratio and phase difference between the incident and reflected beam.

Because the wax films are ultrathin, it is difficult to distinguish film thickness from its matching refractive index. Following previous studies of AFM, SE and NR, the wax film could be regarded as consisting of a uniform underlying layer of fixed refractive index and a second layer describing the diffuse surface wax crystalline extrusions present upon the film surface. ${ }^{22}$ The same model was adopted here in the SE analysis of the wax film/water interface by fixing $\tau$ of

$52 \pm 1 \AA$ for the inner underlying layer and that of $100 \pm 5 \AA$ for the outer diffuse wax crystalline 
extrusion. As already outlined in the Experimental Section, SE measures the wavelength dependence of the wax film's refractive index, $n$, over the visible-UV spectral region using an appropriate optical model to give an improved description of the measured optical properties. These properties were described by applying a 2-layer Cauchy fit to the measured data, in the form $n=A+B / \lambda^{2}$ where $A$ and $B(\mu m)$ are constants to be fitted. The Cauchy model provides a good fit to the measured data across the entire wavelength range, and the best-fit to the inner wax film led to $\left.n_{\text {film }}=1.45+0.01 / \lambda^{2}\right)$, corresponding to $\sim 30 \%$ water penetration $\left(\left[n_{f i l m}-\right.\right.$ $\left.\left.n_{\text {water }}\right] /\left[n_{\text {wax }}-n_{\text {water }}\right] ; n_{\text {water }}=1.33\right)$. From the best-fitting model it could be inferred that the wax film is largely transparent (absorption coefficient, $k=0$ ) with a slight wavelength dependence which influenced the fitting quality. The amount of water mixing is consistent with our previous work from the combined SE and NR measurements. ${ }^{22}$ Likewise, the second layer describing the surface crystalline extrusions was fitted with $n_{\text {film }}=1.355+0.005$, corresponding to $\sim 83 \%$ water penetration.
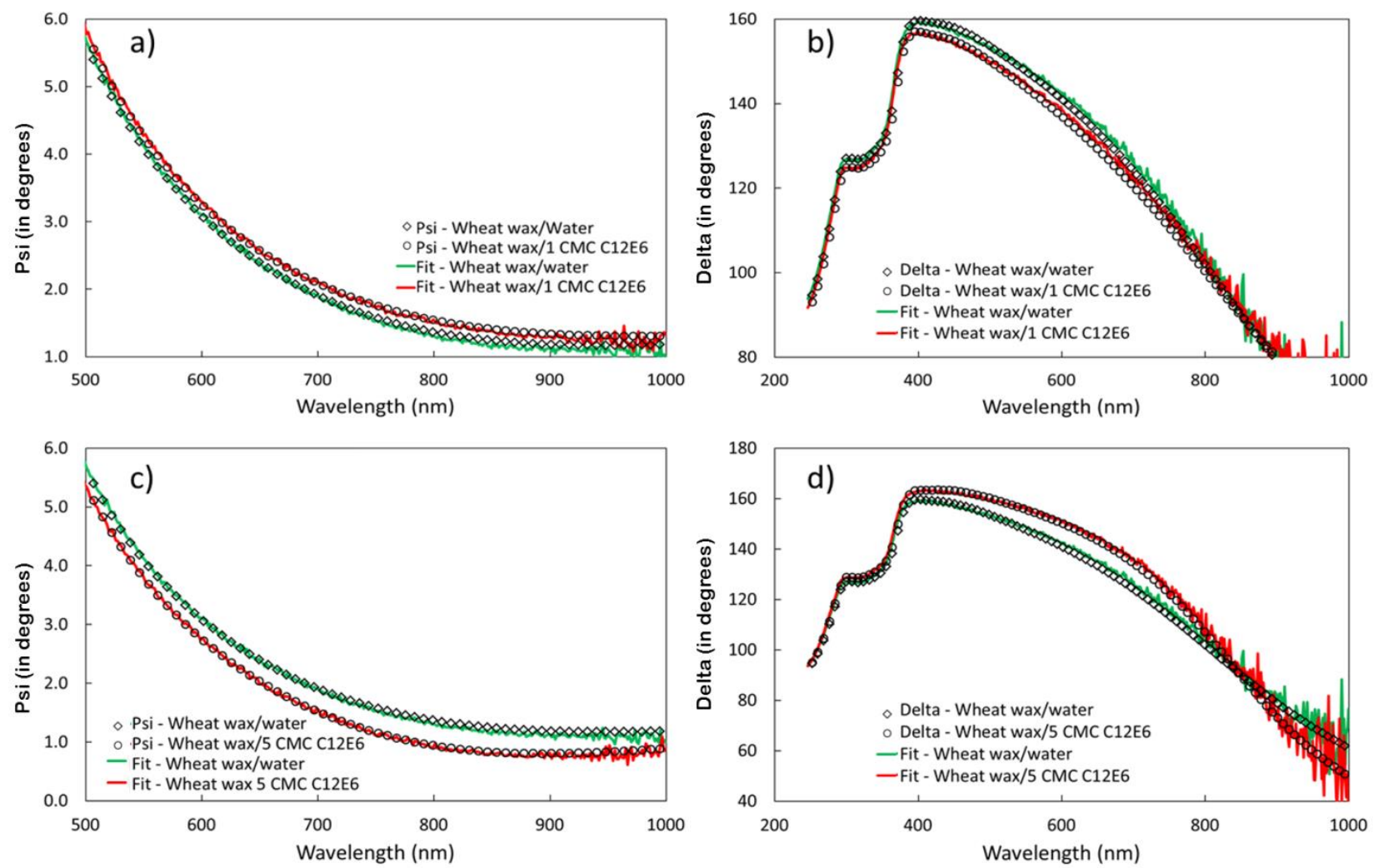

Figure 1: The experimental $\Psi$ (Psi) and $\Delta$ (Delta) profiles measured at the incidence angle of $70^{\circ}$ from SE with the best fits describing changes in $\Psi$ and $\Delta$ before and after $\mathrm{C}_{12} \mathrm{E}_{6}$ binding, 
measured over the wavelength range $200-1000 \mathrm{~nm}$, with (a) and (b) showing $\Psi$ and $\Delta$ profiles obtained from the wax film before and after binding with $\mathrm{C}_{12} \mathrm{E}_{6}$ at the $\mathrm{CMC}$ and (c) and (d) showing the profiles with and without $\mathrm{C}_{12} \mathrm{E}_{6}$ at $5 \mathrm{CMC}$. The difference between these two sets of data indicates the different extent of binding and possible consequential effect to the wax film at and above CMC.

Figure 1 shows the best-fits modelling the $\Psi$ and $\Delta$ profiles measured from the solid/water interface with the wax film coated, and the good fits to the measured data indicate that the model wax films could be reproduced. Addition of surfactant caused changes to the measured $\Psi$ and $\Delta$ profiles as evident from Figure 1, but with adjustments to the 2-layer model, good fits could also be obtained to those measured at surfactant concentrations of $\mathrm{CMC}$ and $5 \mathrm{CMC}$. Comparisons given in Figure 1 thus reveal that surfactant binding leads to visible changes in $\Psi$ and $\Delta$ profiles that could be modelled by the 2-layer model from SE measurements.

As already indicated, however, SE lacks the sensitivity to decouple thickness from refractive index over the film thickness range studied. This was especially the case when modelling the outer extrusion region as SE could not accurately model the thickness of the known crystalline extrusions diffusely scattered upon the wax film surface due to the low contrast in the layer's refractive index when compared to the solvent. In spite of these limitations, the mass of the wax film and the net mass change upon surfactant binding could be accurately calculated from SE data using De Feijter's formula (Equations (1) and (2)). The associated mean-squared errors (MSE) reported for SE were around 3.5, indicating the high quality of the fits. ${ }^{39}$

The refractive index of $\mathrm{C}_{12} \mathrm{E}_{6}$ is 1.455 , close to that of 1.478 for the wax. The similarity in the refractive indices of the surfactant and wax means that although it is difficult to distinguish the two the binding of surfactant to the wax film did not require any modifications to the model adopted. The relative SE changes could be attributed to surfactant binding. Changes in layer mass were simply calculated from Equations (1) and (2) from changes in the fitted refractive index and thickness due to the deposition and removal of surfactant. Figure 2 depicts the set of experimental observations of mass changes from SE, incorporating the intermediate water rinsing steps to 
demonstrate the extent of reversible adsorption and impact to the wax film. It begins with the control run from the bare wax film in pure water, followed by the injection of $\mathrm{C}_{12} \mathrm{E}_{6}$ solutions and subsequent water rinsing steps in the order of increasing $\mathrm{C}_{12} \mathrm{E}_{6}$ concentration. The mass of the wax film was found to be $5.09 \pm 0.12 \mathrm{ng} / \mathrm{mm}^{2}$ from the 2-layer model fit, with the underlying film occupying $3.52 \mathrm{ng} / \mathrm{mm}^{2}$ and the outer extrusion layer with a mass of $1.58 \mathrm{ng} / \mathrm{mm}^{2}$.

As surfactant solutions at concentrations of $0.1 \mathrm{CMC}, 0.5 \mathrm{CMC}$ and $\mathrm{CMC}$ were introduced to the wax film, the net mass was found to increase by $0.22,0.54$ to $1.71 \mathrm{ng} / \mathrm{mm}^{2}$, respectively. It was assumed that over the concentration range studied surfactant binding or removal did not cause any structural change to the wax film. As evident from Figure 2, all surfactant molecules bound during adsorption could be removed during subsequent rinsing, justifying the assumption about the retaining of the wax film structure during the adsorption-desorption process. It can also be seen from Figure 2 that as surfactant concentration increases the amount of surfactant adsorbed also increases. At CMC, the thickness of the wax film increases by $20.5 \AA$, to $72.7 \pm 2 \AA$, corresponding to the mass change of $1.71 \mathrm{ng} / \mathrm{mm}^{2}$. This steady increase in surfactant binding and the total mass of the film is a clear indication of the affinity of the surfactant to the wax film. The returning of the mass of the wax film after water rinsing added confidence to the perceived retaining of the wax film structure below CMC. 

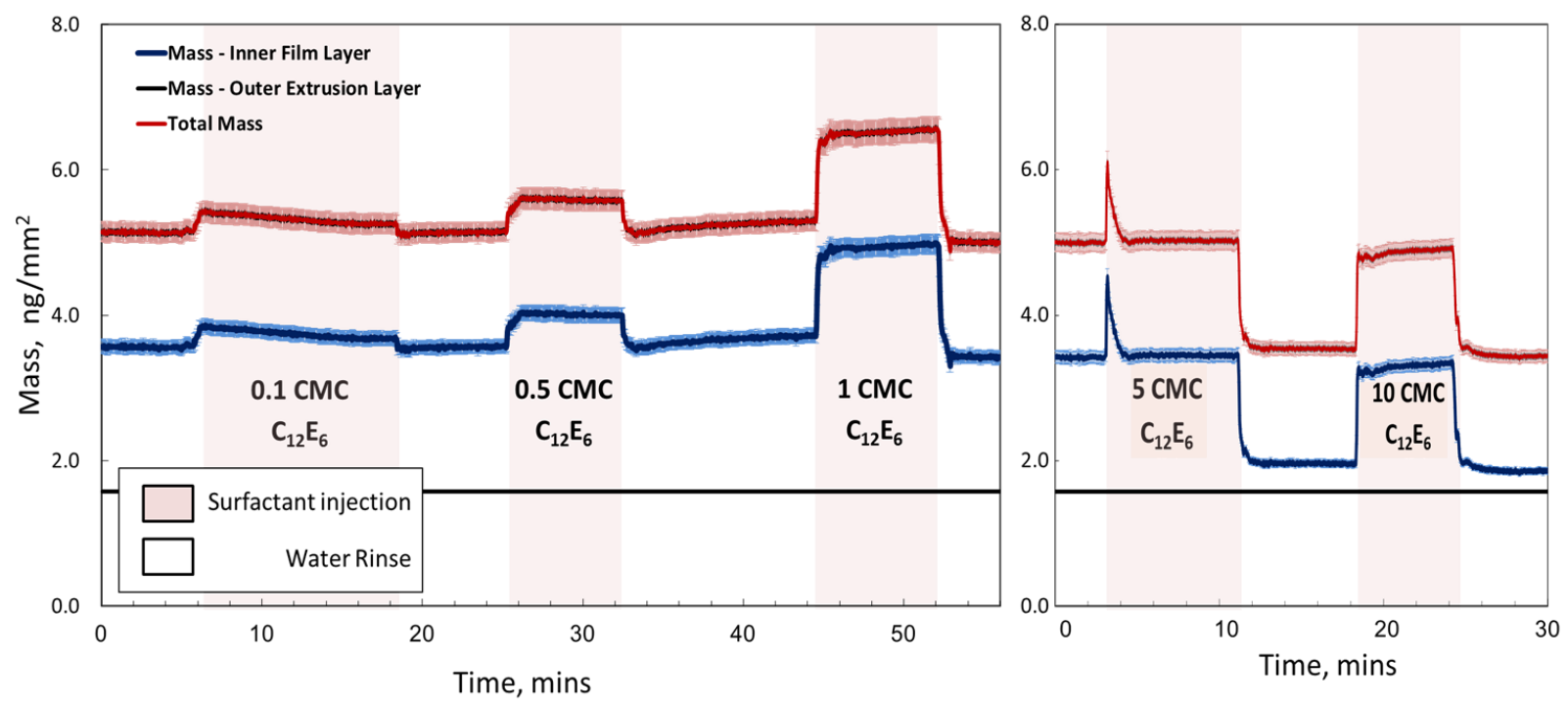

Figure 2: A sequential set of dynamic SE measurements plotted in the form of the change in mass, $\Delta m$, of the measured wax film as $\mathrm{C}_{12} \mathrm{E}_{6}$ binding occurs in order of increasing concentration, followed by a rinsing step after each solution injection. Measurements were obtained at $0,0.1$ CMC, 0.5 CMC, CMC, 5 CMC and $10 \mathrm{CMC}$. The total mass of the wax film at the solid/water interface was $5.09 \mathrm{ng} / \mathrm{mm}^{2}$ at the start. Error bars marked in light blue.

Apart from the trend of increasing surfactant binding to the wax film with surfactant concentration, the data shown in Figure 2 also reveals the fast dynamic processes upon adsorption and desorption. It only took seconds for dynamic processes in either adsorption or desorption to complete. Water rinsing of the surfactant at the CMC led to the shift of the measured mass to just below that of the previous control baseline $\left(5.09 \mathrm{ng} / \mathrm{mm}^{2}\right)$, indicating the removal of a small amount of the wax film. At $5 \mathrm{CMC}$, initial surfactant binding clearly showed strong affinity to the wax film causing a net mass increase of $1.3 \pm 0.2 \mathrm{ng} / \mathrm{mm}^{2}$, but after the initial sharp rise some of the surfactant and surfactant-wax mixtures became removed. A similar trend was observed at 10 $\mathrm{CMC}$, however, the amount of wax removal was similar.

Above $\mathrm{CMC}, \mathrm{C}_{12} \mathrm{E}_{6}$ forms spherical or slightly elliptical micelles which work as carriers to help remove oily stains via solubilization, a well-known action of its detergency. ${ }^{25,40,41}$ The SE measurements, as shown in Figure 2, reveal this micellar detergency action in removing the wax film at and above the CMC. Water rinsing carried out after the 3 consecutive exposures to the surfactant at and above the CMC resulted in mass loss increasing from $10 \%$ to $40 \%$ as the wax 
was solubilized. The detergency effects occurring above CMC switched the relative sequential order as observed from the $\Psi$ and $\Delta$ profiles between $0.5 \mathrm{CMC}$ (Figure 1a, b) and 5 CMC (Figure 1c, d) against the control ones measured from the wax film/water interface.

\section{Surfactant binding measured from neutron reflection (NR)}

NR measurements at the solid/liquid interface were carried out to provide the structural details underlying surfactant binding and wax removal below and above CMC. Similar to the experimental procedures as described for $\mathrm{SE}$, solutions of both fully protonated $\mathrm{hC}_{12} \mathrm{E}_{6}$ and chaindeuterated $\mathrm{dC}_{12} \mathrm{E}_{6}$ of increasing concentrations were brought in contact with the model cuticular wheat wax film, with each adsorption being followed by a rinsing process.

Using the aforementioned Hughes error function model ${ }^{22,38}$, the wax film coverage, distribution and the extent of water penetration were obtained from the best-fitted density profiles. Using Equation (4), the volume fraction of the wax film, $\phi_{\text {wax }}$, in the presence of water, at any particular distance, $z$, from the silicon interface could be determined from the constructed SLD profile by the total SLD contributions from both the wax film, $\rho_{\text {wax }}$, and $\mathrm{D}_{2} \mathrm{O}, \rho_{D 2 O}$ :

$$
\rho(z)=\sum \phi_{m}(z) \rho_{m}, \text { where } \sum \phi_{m}=1 \text {, at a distance, } z \text {, from interface. }
$$

where $\phi_{m}$ is the volume fraction occupied by constituent material $m$, with scattering length density $\rho_{m}$, respectively, at any particular distance, $z$, away from the interface. In the context of this work, $\mathrm{z}$ was set to 0 on the surface of silicon oxide and its positive direction was into the bulk water. The SLD of the wheat wax, $\rho_{w a x}$, is $-0.3 \times 10^{-6} \AA^{-2}$ and that for $\mathrm{D}_{2} \mathrm{O}$ is $\rho_{D 2 O}=6.35 \times 10^{-6} \AA^{-}$ ${ }^{2}$. From these values, the volume fraction profiles showing the water and wax present in the wax film were determined from the reflectivity modelling prior to surfactant introduction. As evident from Figure 5, the $\operatorname{SLD}(\rho(z=0))$ of the wax film measured at the $\mathrm{SiO}_{2} /$ wax interface was $1.46 \times 10^{-6} \AA^{-2}$, giving the wax volume fraction, $\phi_{w a x},=0.75$ from Equation (4).

In the presence of surfactant, the volume fractions of surfactant, wax and water at any distance, $z$, from the interface could be similarly determined from Equation (4). Figure 3 shows the set of reflectivity profiles measured at several representative $\mathrm{hC}_{12} \mathrm{E}_{6}$ concentrations and Figure 4 shows 
the set of the reflectivity profiles measured at several $\mathrm{dC}_{12} \mathrm{E}_{6}$ concentrations, all in $\mathrm{D}_{2} \mathrm{O}$. The measured NR profiles were fitted with representative models corresponding to the 2-layer wax film structure as established previously, to allow for an unambiguous determination of the surfactant's influence upon the structure and density distribution of the reconstituted wax film. Both $\mathrm{dC}_{12} \mathrm{E}_{6}$ and $\mathrm{hC}_{12} \mathrm{E}_{6}$ measurements carried out at the same concentrations were described in terms of their volume fraction profiles as shown in Figure 5, and the resultant best-fitted reflectivity profiles are shown as continuous lines in Figures 3 and 4. Tables S3 and S4 list the best-fitted parameters and a more extensive set of NR profiles depicting the best-fitted models to reflectivity profiles measured under different surfactant concentrations can be found from Figures S2-S12 from $\mathrm{hC}_{12} \mathrm{E}_{6}$ adsorption and Figures $\mathrm{S} 13-\mathrm{S} 22$ from $\mathrm{dC}_{12} \mathrm{E}_{6}$ adsorption in $\mathrm{D}_{2} \mathrm{O}$ in the Electronic Supplementary Material.

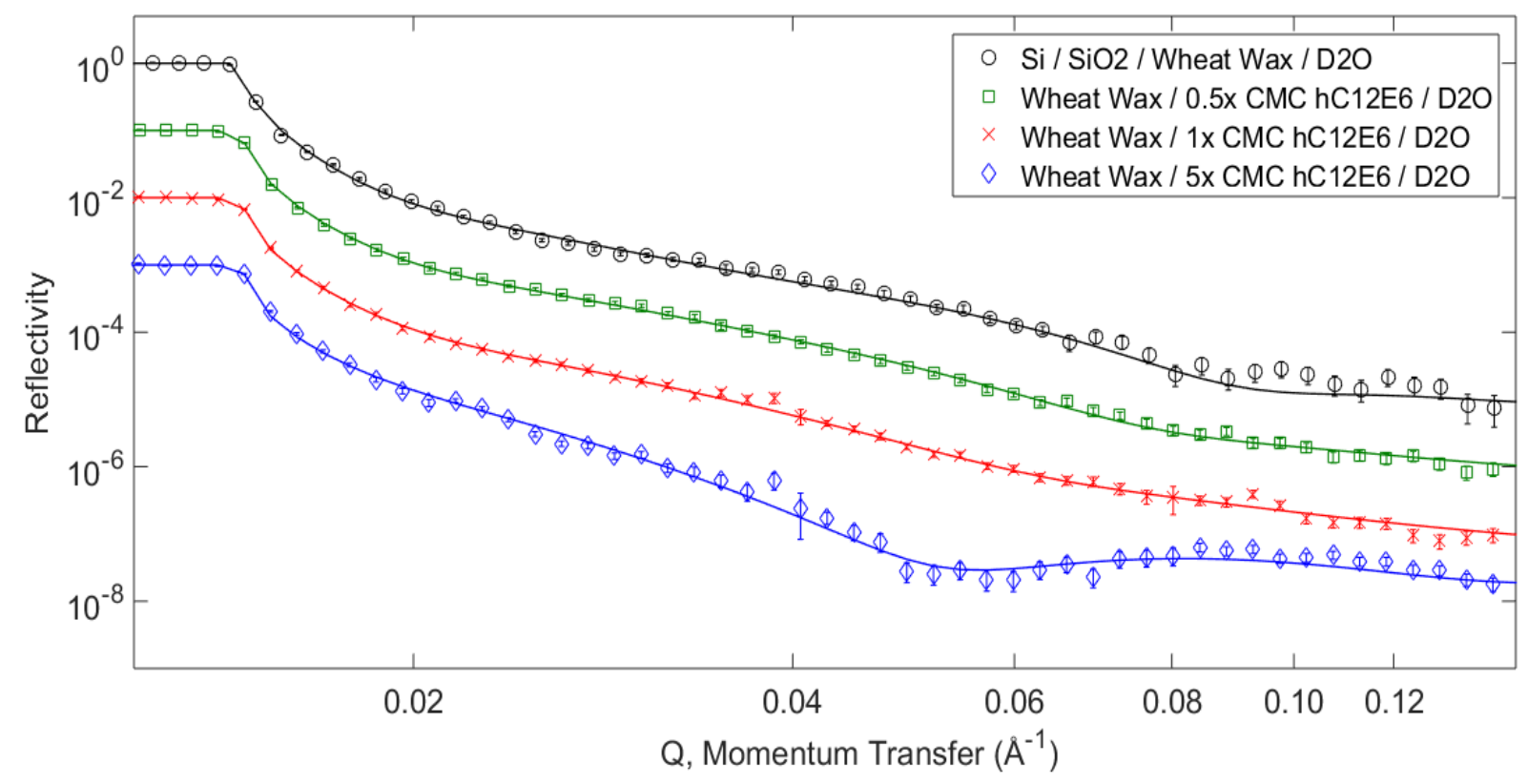

Figure 3: Reflectivity profiles plotted against momentum transfer, $Q$, at the silicon $/ \mathrm{D}_{2} \mathrm{O}$ interface, with a reconstituted wheat wax film coated onto the $\mathrm{SiO}_{2}$ surface (O). Subsequent measurements were made also in $\mathrm{D}_{2} \mathrm{O}$ containing $\mathrm{hC}_{12} \mathrm{E}_{6}$ at concentrations of $0.5 \mathrm{CMC}(\square), \mathrm{CMC}$ $(\times)$ and $5 \mathrm{CMC}(\diamond)$. Insets show the zoomed reflectivity regions depicting the main changes arising from surfactant binding to the wax film. The continuous lines represent the best 2-layer model fits with the corresponding structural parameters given in Tables S3, S4. A flat background of 6 to $8 \times 10^{-6}$ was applied to all fits. 
The main observation from the NR results is the mixing of a large amount of water into the wax film, in agreement with our previous study carried out upon similar reconstituted wheat wax films. ${ }^{22}$ More specifically, the volume fraction of wax decreases with $\mathrm{z}$, as shown in Figure 5. Close to the $\mathrm{SiO}_{2}$ surface, the wax volume fraction was about 0.7 but then rapidly increased to about 0.2 at the outer surface of the underlying film, with its full thickness around $100 \AA$. The thickness and shape of the density distribution profile of the underlying wax film is described by a best-fitted layer thickness, $\tau$, of $65 \AA$ and an associated Gaussian roughness parameter, $\sigma$, of 20 $\AA$ (Figure 5).

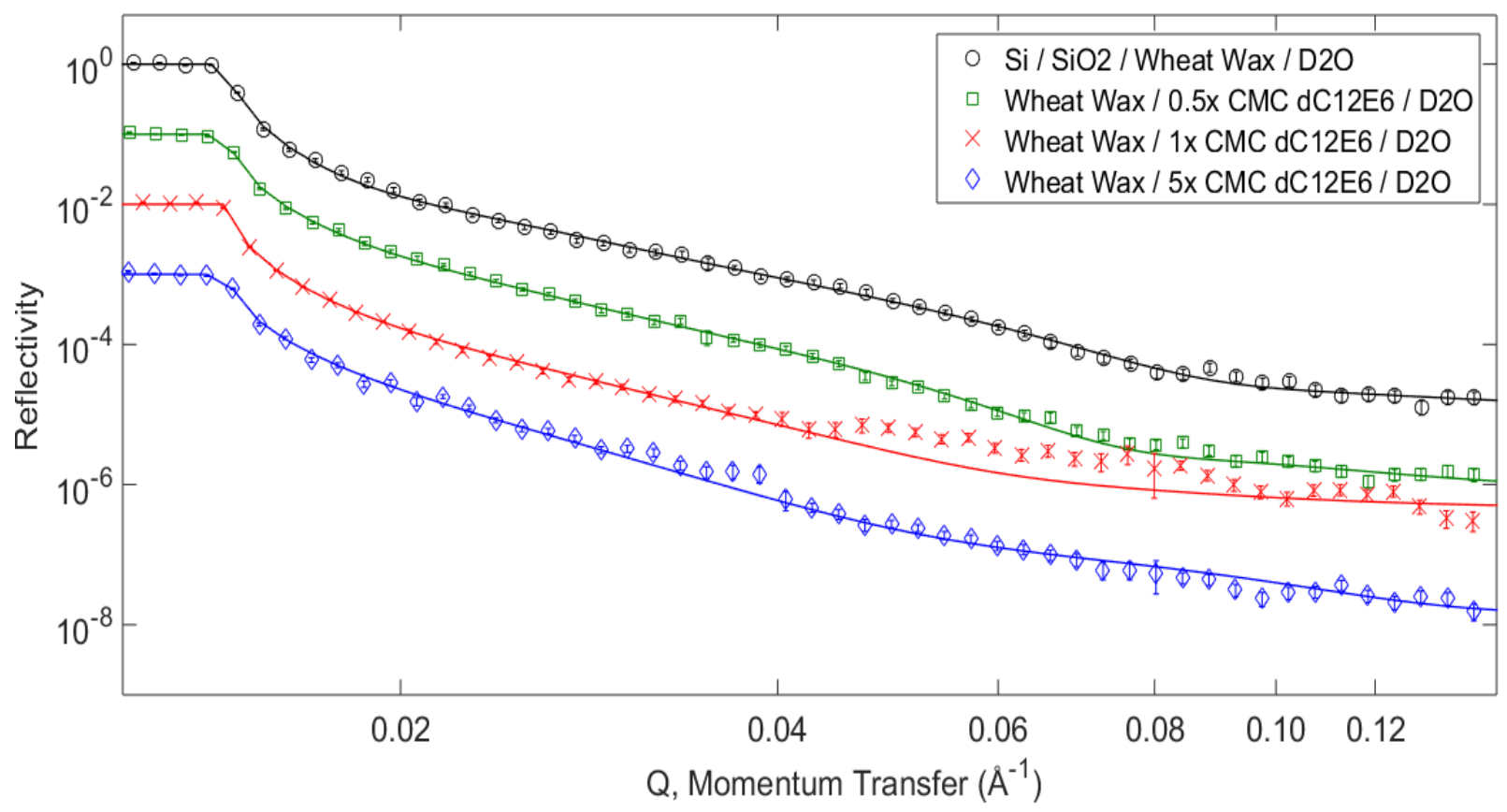

Figure 4: Reflectivity profiles plotted against momentum transfer, $Q$, at the silicon/ $\mathrm{D}_{2} \mathrm{O}$ interface, with a reconstituted wheat wax film coated onto the $\mathrm{SiO}_{2}$ surface (O). Subsequent measurements were made also in $\mathrm{D}_{2} \mathrm{O}$ containing $\mathrm{dC}_{12} \mathrm{E}_{6}$ at concentrations of $0.5 \mathrm{CMC}(\square), \mathrm{CMC}$ $(\times)$ and 5 CMC $(\diamond)$. The continuous lines represent the best 2-layer fits with the corresponding structural parameters given in Tables S3, S4. A flat background of 6 to $8 \times 10^{-6}$ was applied to all fits. 
Accompanying the decreasing wax volume fraction was the steady increase in water content with increasing distance from the silicon oxide surface. Close to the interface at $\mathrm{z}=0$, the volume fraction of water was about 0.3 . Over the first $50 \AA$ of the underlying wax film, water content increased slightly but it became doubled over the next $50 \AA$ - pointing towards a highly diffuse and porous film for the easy passage of water. In contrast, the volume fraction of water was over 0.8 for the crystalline extrusion layer. In addition to its high water content, this layer is characterized by its large thickness and diffusiveness, with fitted $\tau$ of $125 \AA$ and $\sigma$ of $105 \AA$ corresponding to a fast decreasing wax volume fraction profile matching the interfacial distance increase from $100 \AA$ to $400 \AA$ as shown in Figure 5 .

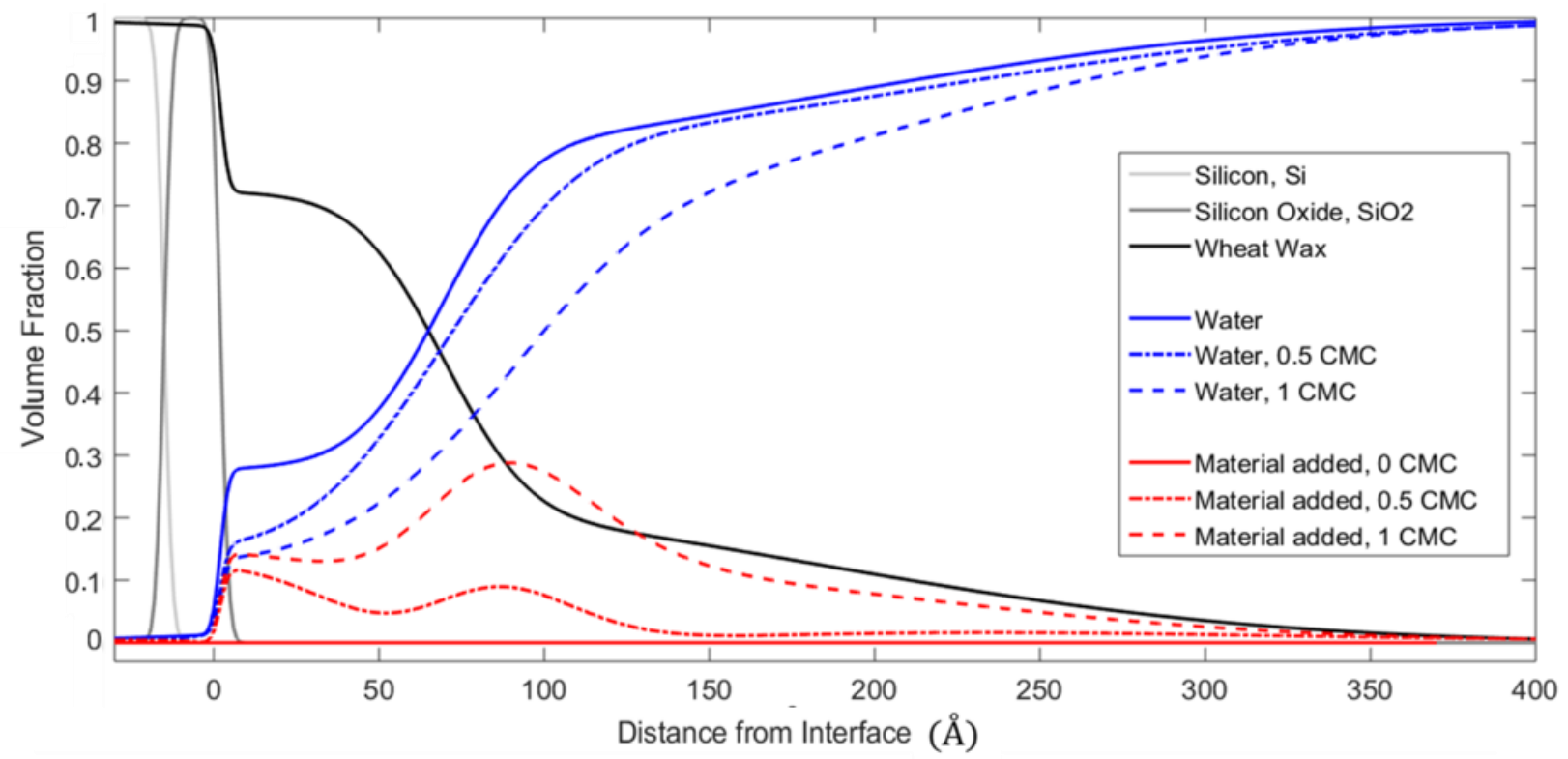

Figure 5: Volume fraction profiles describing the distribution of the wax film at the silicon/ $\mathrm{D}_{2} \mathrm{O}$ interface, with a reconstituted wheat wax film coated onto the $\mathrm{SiO}_{2}$ surface (solid black line) and the corresponding water distribution (solid blue line). Subsequent binding of surfactant at 0.5 CMC and CMC led to the decline of water volume fraction as a result of surfactant binding and the rising amount of surfactant associated, shown as short and long dashed lines, respectively, with the same color scheme.

The structural features from the wax film as depicted in Figure 5 are consistent with our previous observations studied by combined measurements of AFM, cryo-SEM and NR. ${ }^{22}$ Wax films carry regularly distributed nanoscale crystalline wax extrusions which cause off-specular or diffuse 
scattering. This feature was well illustrated in our previous neutron reflection work utilising a 2dimensional detector. ${ }^{22}$ As nonionic surfactant solutions are introduced to the reconstituted wheat wax film at concentrations below $\mathrm{CMC}$, surfactant molecules may adsorb onto the hydrophobic wax surface forming an additional interfacial layer that effectively broadens the thickness of the wax film. Due to their porous nature, however, the modelling of the measured NR profiles could just reveal the mixing of surfactant with the wax film without the capability to distinguish adsorption from penetration or absorption from $\mathrm{hC}_{12} \mathrm{E}_{6}$ (Figure 3) and $\mathrm{dC}_{12} \mathrm{E}_{6}$ (Figure 4). As in the case of SE, however, it can still be assumed that the structure and volume fraction distribution of the wax film, $\phi(z)_{\text {wax }}$ remained unchanged after surfactant deposition and removal by rinsing. By rearranging Equation (4) for a 3-component structure, the influence of surfactant upon the SLD of the wax film alongside the water volume fraction distribution, $\phi(z)_{\text {water }}$, is determined by

$$
\phi(z)_{\text {water }}=\frac{\left[\rho(z)_{\text {total }}-\rho_{\text {wax }} \phi(z)_{\text {wax }}-\left(1-\phi(z)_{\text {wax }}\right) \rho_{\text {surf }}\right]}{\rho_{\text {water }}-\rho_{\text {surf }}}
$$

where $\rho_{\text {surf }}, \rho_{\text {water }}$ and $\rho_{\text {wax }}$ are the known SLD values for $\mathrm{C}_{12} \mathrm{E}_{6}, \mathrm{D}_{2} \mathrm{O}$ and wheat wax, and $\rho_{(z) \text { total }}$ is the SLD distribution profile calculated from the best-fitted model. Profiles of wax and water distributions as shown in Figure 5 for surfactant concentrations of 0, 0.5 CMC and CMC also allow the respective volume fraction distribution of $\mathrm{C}_{12} \mathrm{E}_{6}$ in the wax film to be derived from Equation (6).

$$
\phi(z)_{s u r f}=1-\phi(z)_{w a x}-\phi(z)_{w a t e r}
$$

The model fitting to the NR profiles of Figures 3 and 4 revealed that the thickness of the underlying wax film increased from $\sim 100 \AA$ to $130 \AA$ as surfactant concentration increased from $0.05 \mathrm{CMC}$ to $\mathrm{CMC}$, broadly consistent with the adsorption of $\mathrm{C}_{12} \mathrm{E}_{6}$ from $\mathrm{SE}$ and other studies. $^{26,30,42,43}$ This thickness increase is explained in Figure 5 by the shape change of the volume fraction distribution profile of the wax film measured at different $\mathrm{C}_{12} \mathrm{E}_{6}$ concentrations. As concentration is increased to $\mathrm{CMC}$, the outer surface extrusion layer is shifted away from the $\mathrm{SiO}_{2}$ surface, indicating an increased underlying film thickness. 
As implicated by the stable wax film and reversible nature of surfactant binding and removal, water present within the wax film was displaced by the deposited $\mathrm{C}_{12} \mathrm{E}_{6}$ molecules. From the measured SLD fraction profiles, the amount of the nonionic surfactant associated with the wax film was determined. The surfactant mass per unit area, $\Delta m$ due to surfactant deposition can be calculated for neutron reflection by using:

$$
\Delta m=\rho_{\text {surf }} \int_{0}^{z} \phi(z)_{\text {surf }} d z
$$

where $\phi(z)_{\text {surf }}$ is the surfactant volume fraction at $z$, and $\rho_{\text {surf }}$ is the density of $\mathrm{C}_{12} \mathrm{E}_{6}(\rho \approx 0.98,>$ $99 \%)$

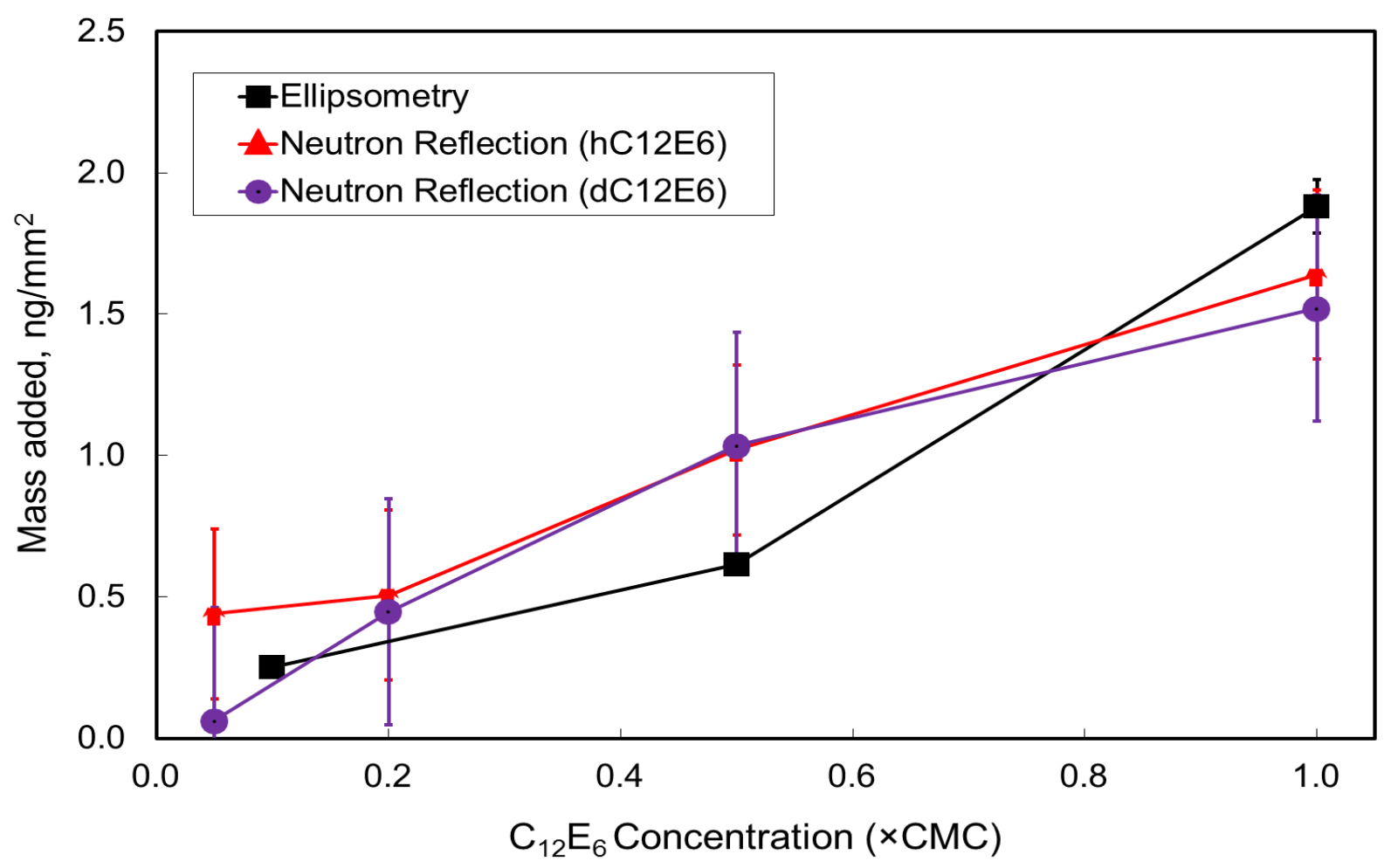

Figure 6: Mass changes upon binding of $\mathrm{C}_{12} \mathrm{E}_{6}$ to the wax film are plotted against its bulk concentration up to the CMC measured from SE and NR (involving both $\mathrm{dC}_{12} \mathrm{E}_{6}$ and $\mathrm{hC}_{12} \mathrm{E}_{6}$ ). In spite of large errors below CMC the data from SE and NR as shown here are still consistent. Above CMC, discrepancies become large due to the wax film instability associated with partial removal arising from increasing detergency with surfactant concentration (not shown here).

Changes in the amount of $\mathrm{C}_{12} \mathrm{E}_{6}$ bound to the wax film as a result of the adsorption and absorption with increasing concentration are also shown in Figure 6, where measured mass changes upon surfactant deposition from NR and SE are compared. The results from both SE and 
NR were very consistent up to CMC in spite of large errors as marked in Figure 6. Above CMC, wax films become more unstable, causing even larger uncertainty in the determination of the amount of wax remaining and amount of surfactant associated.

Thus, even over the concentration range below $\mathrm{CMC}$, surfactant molecules can penetrate into the wax film, implying that active ingredients in pesticides could also diffuse through the wax film by the same process. As evident from water rinsing after $\mathrm{C}_{12} \mathrm{E}_{6}$ adsorption, the surfactant can be removed from the wax film without structural compromise, showing that the surfactant must interact reversibly with the wax film, leaving the wax film in its original state. These observations point towards the likely scenario of penetration of $\mathrm{C}_{12} \mathrm{E}_{6}$ molecules through the porous network within the wax film. Figure 7 schematically depicts the wax-surfactant interaction below CMC where it can be seen that nonionic surfactants such as $\mathrm{C}_{12} \mathrm{E}_{6}$ can adsorb on the wax film surface and absorb into the porous bulk as well. The latter may well enhance the transport of water and active ingredients across the waxy barrier.

Cuticular wax films are comprised of mixed compounds with long aliphatic chains, most of which contain small polar groups such as hydroxyl groups at the terminals. Whilst some of these compounds can phase separate to form wax crystals with different morphological features, little is known about the micro- and nano-structures formed within the underlying wax films. The presence of the porous network within the cuticular wax film may explain the permeability of cuticular waxes which plays an active role in regulating transport through plant surface barriers. ${ }^{15,20}$ Riederer et al. and others attributed the observed increase in water permeability through extracted waxes upon interaction with nonionic surfactants to the penetration of the surfactants through the cuticular wax structures, causing structural modifications. ${ }^{21,44,45}$ Their work was carried out on bulk wax samples as opposed to reconstituted ultrathin film models. It is however difficult to envisage the formation of the sponge-like structural features in bulk waxes as in the ultrathin wax films due to the very low diffusion coefficients of the order of $\sim 10^{-16}$ to $10^{-18}$ $m^{2} s^{-1}$ as observed. ${ }^{15,20,21}$ These diffusion coefficients are several orders of magnitude lower than 
what are expected in real cuticular wax films and would prevent the transport of water and active ingredients through them. In contrast, the scale known to occur on crop surfaces in nature would require another mechanism to explain the observed permeability. ${ }^{4,46}$

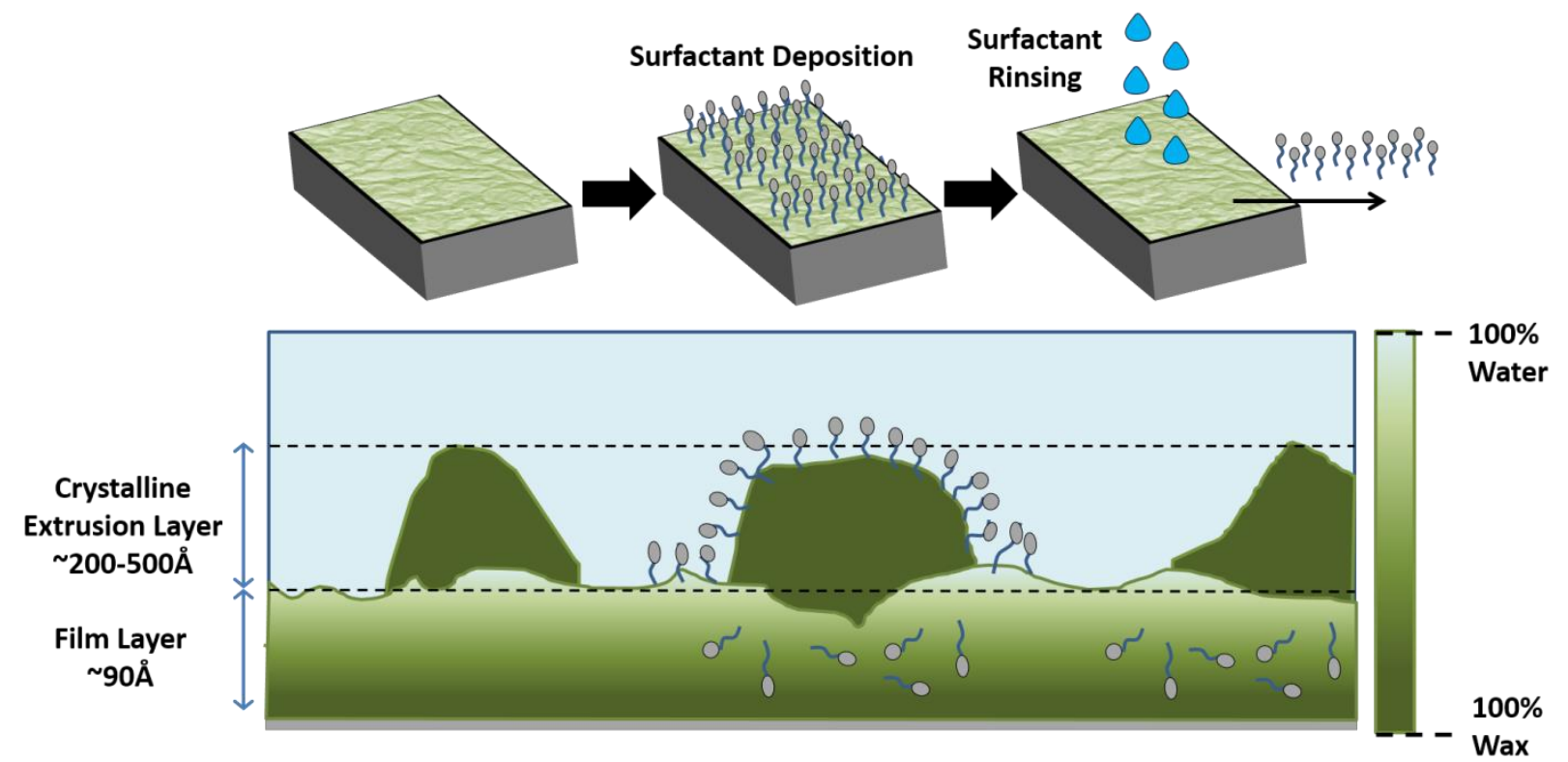

Figure 7: Speculative representation of the lateral structure consisting of an underlying wax layer and outer surface extrusions as revealed from NR. These structural features are well represented from the 2-layer model with the underlying film having a thickness of $\sim 80-100 \AA$ and the extrusion layer having a thickness ranging from 200 to $500 \AA$. When $\mathrm{C}_{12} \mathrm{E}_{6}$ surfactants are exposed to the wax film surface below the $\mathrm{CMC}$, they become adsorbed and absorbed, replacing water molecules across the film. As the surfactant solution is removed and replaced by water these interfacially bound surfactants are washed away and the film structure is largely retained.

\section{Wax removal measured by NR}

As surfactant concentration was increased from $\mathrm{CMC}$ to $5 \mathrm{CMC}$ the thickness of the underlying wax film decreased dramatically from $\sim 130 \AA$ to $\sim 50 \AA$, as indicated by the direction of the arrow showing the shift in the water volume fraction profile in Figure 8. The position of the inflection point which defines the emergence of the surface extrusion region tends towards the substrate surface while also indicating an increase in water content as surfactant concentration is increased. The thickness change is mainly attributed to wax removal due to the detergency action of the nonionic $\mathrm{C}_{12} \mathrm{E}_{6}$ micelles formed above $\mathrm{CMC}$. The increased water content also signifies changes to the structural integrity of the wax film. The associated mass losses of the wax films upon 
exposure to $5 \mathrm{CMC} \mathrm{C}_{12} \mathrm{E}_{6}$ were calculated as $-2.2 \pm 1.0 \mathrm{ng} / \mathrm{mm}^{2}$ for $\mathrm{hC}_{12} \mathrm{E}_{6}$ using $\mathrm{NR}$, from an initial mass value, whilst SE detected a mass loss of around $-2.1 \pm 0.2 \mathrm{ng} / \mathrm{mm}^{2}$, corresponding to $\sim 40 \%$ of the underlying wax film (Figure 2). Reproducible results were not obtained at 5 CMC for $\mathrm{dC}_{12} \mathrm{C}_{6}$ using $\mathrm{NR}$, caused by poor contrast resolution. Large discrepancies arose from the difficulty in controlling or replicating the exact amount of wax removal under these conditions caused by the instability of the wax films under attack from the surfactant.

Gravimetric measurements carried out by various previous studies have suggested that surfactant treatment does not have a measurable effect upon the amount or composition of the cuticular waxes extracted..$^{21}$ A possible explanation for the observation is that these measurements were again carried out from bulk plant cuticular waxes extracted instead of nano-scale wax thin film models as measured by NR and SE in this work.

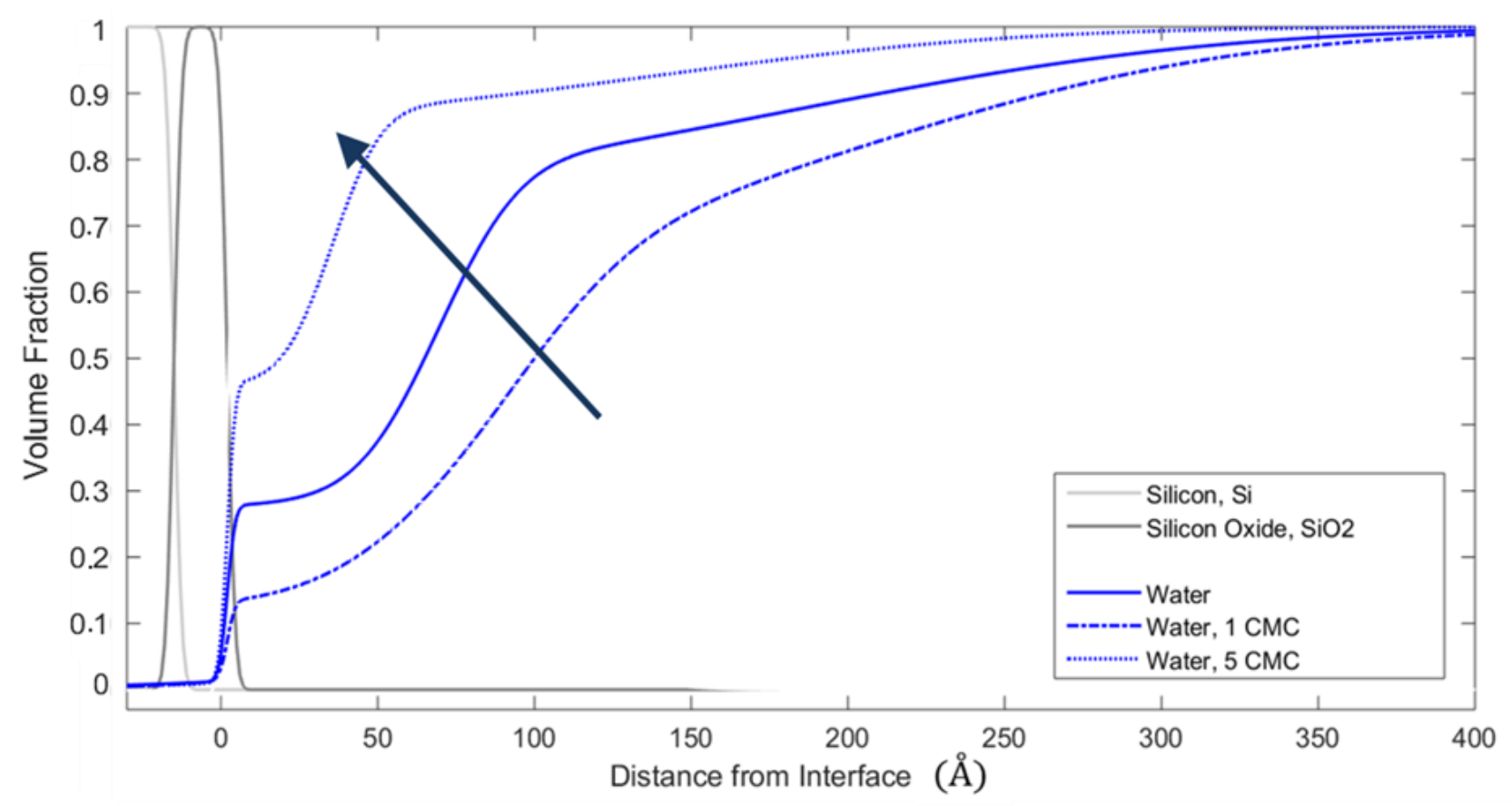

Figure 8: Water volume fraction profiles within the underlying wax film as $\mathrm{hC}_{12} \mathrm{E}_{6}$ surfactant concentration goes from 0 to $\mathrm{CMC}$ and $5 \mathrm{CMC}$. The initial surfactant increase up to CMC led to the extent of water inside the wax film declining from surfactant binding, but further increase the surfactant concentration above CMC caused wax removal and the volume fraction of water to increase. 
The schematic as shown in Figure 9 depicts the structural changes to the integrity of the reconstituted wheat wax film due to the micellar detergency action above CMC. It is clear from $\mathrm{NR}$ and SE that the irreversible damage caused by surfactants above CMC would have a significant influence upon the transport properties of the wax film via its partial removal as the barrier to transport. This result could open the door into investigating the idea of using surfactants in advanced formulations which can mediate the extent of interactions with a plant's wax barrier, regulating the transport process across leaves whilst causing no harm to plants.

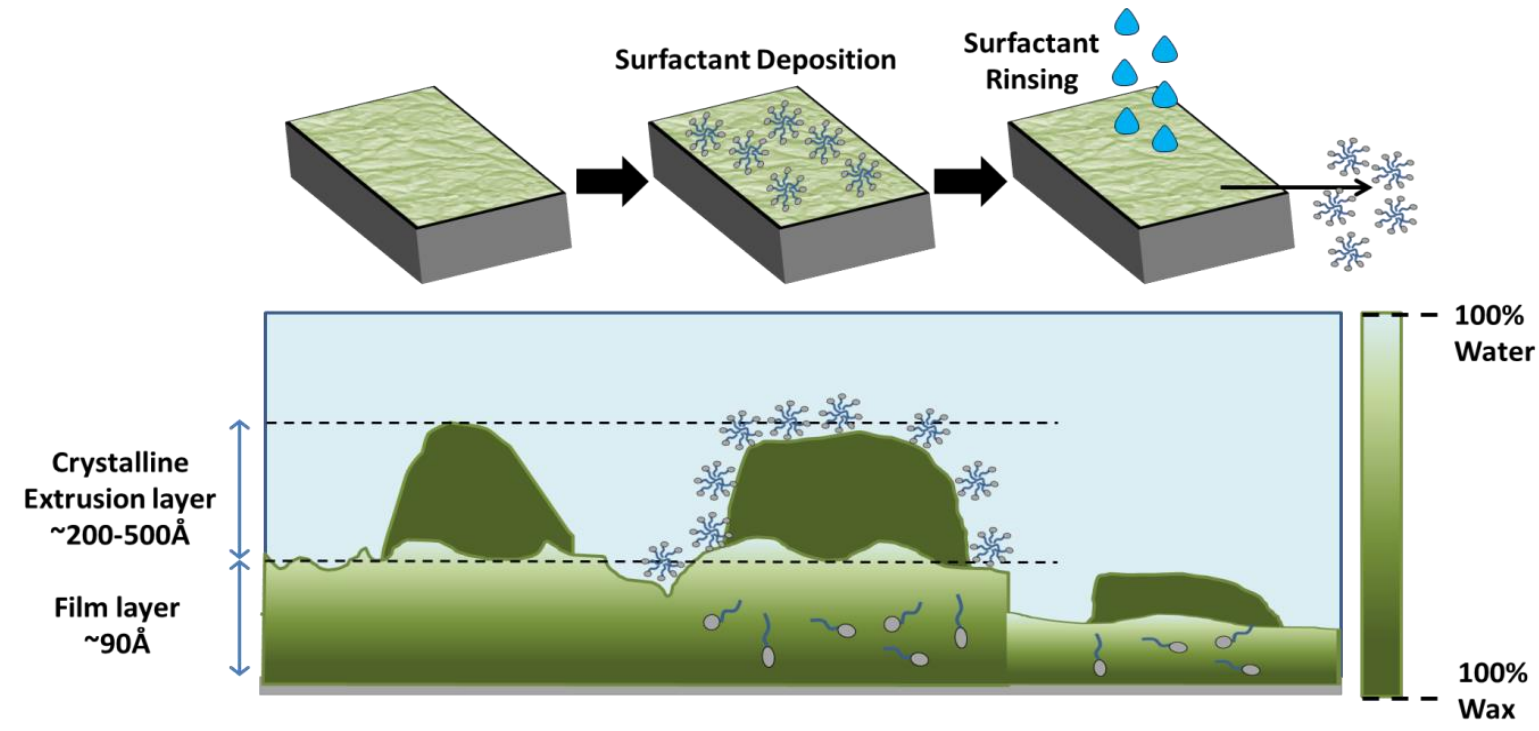

Figure 9: Speculative representation of the lateral structure. Above $\mathrm{CMC}, \mathrm{C}_{12} \mathrm{E}_{6}$ micelles attack the wax film and solubilize its constituents. In the meantime, surfactants can also penetrate the porous regions along with water molecules. These actions together help dissolve some of the wax film via surfactant detergency, thereby enhancing transport across plant leaves.

\section{Conclusion}

In spite of widespread use of pesticide and other crop protection products, there is little information regarding the transport of various materials through the cuticular wax barriers present on the surfaces of all crops. Through reconstituting the model wax films onto silicon substrate, we were able to facilitate both spectroscopic ellipsometry and neutron reflection measurements to characterize the structural features of the wheat wax films and their interaction with nonionic 
surfactant, a key ingredient in agri-spray. This study revealed that wax films, known to be hydrophobic and water-repellent and form a vital protective barrier, are in fact permeable to water and larger molecules with the main structural parameters close to the previous findings. The measurements also revealed a reversible adsorption-desorption process below the critical micelle concentration (CMC) of $\mathrm{C}_{12} \mathrm{E}_{6}$, with little impact on the structure of the wax film. At and above CMC, more surfactants were deposited both on and within the wax film, causing partial dissolution and removal of some wax components. As a result, the structure and integrity of the waxes was compromised. As surfactants used in pesticide formulations are applied for crop protection usually above CMC, the detergency action of nonionic surfactants to the wax films of plants is likely to occur. Whilst wax removal can enhance the diffusion of active ingredients, it could also cause damage to crops and increase their vulnerability to pathogens. Further work will investigate if similar wax removal occurs when using surfactant mixtures that can more closely mimic pesticide formulations.

Authors' Contributions: EP carried out wax extraction, lab work, data analysis, participated in the design of the study and drafted the manuscript; $\mathrm{XH}, \mathrm{MC}$ assisted with collection of neutron reflection data; $\mathrm{AH}$ and JW were the instrument scientists at ISIS, helping to collect data and analyze them; PL synthesized the deuterated surfactant; GB, JL conceived, designed and coordinated the study and helped draft the manuscript. All authors gave final approval for publication.

Competing Interests: We have no competing interests.

Funding: EP was funded by an EPSRC Postgraduate (PhD) Case Award voucher (12440611) with financial and operational support provided by Syngenta AG.

\section{Acknowledgements}


We thank the ISIS Neutron Facilities, STFC for the award of Neutron Reflection beam-time. We are grateful to Syngenta, University of Manchester and EPSRC (EP/F062966/1) for support and provision of resources and materials.

\section{Supporting Information \& Data Accessibility}

A list of SLD values used in this study, a description of the methodology used for the determination of the refractive index of the reconstituted wheat wax, a description of the neutron reflection model used in the study and additional neutron reflectometry results are shown in the supporting information document. Supporting neutron reflection data available on request from the corresponding author. RasCAL analysis software available to download from https://sourceforge.net/projects/rscl/.

\section{References}

[1] Barthlott, W.; Neinhuis, C.; Cutler, D.; Ditsch, F.; Meusel, I.; Theisen, I.; Wilhelmi, H., Classification and Terminology of Plant Epicuticular Waxes. Bot. J. Linn. Soc. 1998, 126(3), 237-260.

[2] Koch, K.; Ensikat, H. J., The Hydrophobic Coatings of Plant Surfaces: Epicuticular Wax Crystals and Their Morphologies, Crystallinity and Molecular Self-assembly. Micron 2008, 39(7), 759-772.

[3] Riederer, M.; Schneider, G., The Effect of the Environment on the Permeability and Composition of Citrus Leaf Cuticles .2. Composition of Soluble Cuticular Lipids and Correlation with TransportProperties. Planta 1990, 180(2), 154-165.

[4] Riederer, M.; Schreiber, L., Protecting Against Water Loss: Analysis of the Barrier Properties of Plant Cuticles. J. Exp. Bot. 2001, 52(363), 2023-2032.

[5] Bianchi, G., Plant Waxes: Chemistry, Molecular Biology and Functions; The Oily Press: Glasgow, 1995; pp 175-222.

[6] Baker, E. A.; Batt, R. F.; Martin, J. T. Studies on Plant Cuticle: VII. Nature and Determination of Cutin. Ann. Appl. Biol. 1964, 53(1), 59-65.

[7] Schönherr, J., Resistance of Plant Surfaces to Water Loss: Transport Properties of Cutin, Suberin and Associated Lipids. In Physiological Plant Ecology II; Lange, O. L.; Nobel, P. S.; Osmond, C. B.; Ziegler, H., Eds.; Springer: Berlin Heidelberg, 1982; pp 153-179.

[8] Schonherr, J.; Riederer, M., Foliar Penetration and Accumulation of Organic-Chemicals in Plant Cuticles. Rev. Environ. Contam. Toxicol. 1989, 108, 1-70.

[9] Jetter, R.; Schaffer, S., Chemical Composition of the Prunus Laurocerasus Leaf Surface. Dynamic Changes of the Epicuticular Wax Film During Leaf Development. J. Plant Physiol. 2001, 126(4), 17251737.

[10] Nødskov Giese, B., Effects of Light and Temperature on the Composition of Epicuticular Wax of Barley Leaves. Phytochemistry 1975, 14(4), 921-929.

[11] Baker, E. A.; Martin, J. T., Studies on Plant Cuticle .X. Cuticles of Plants of Related Families. Ann. Appl. Biol. 1967, 60(2), 313-319.

[12] Reynhardt, E. C.; Riederer, M., Structures and Molecular-Dynamics of Plant Waxes .2. Cuticular Waxes from Leaves of Fagus-Sylvatica L and Hordeum-Vulgare L. Eur. Biophys. J. 1994, 23(1), 59-70.

[13] Baker, E. A., Effect of Cuticular Components on Foliar Penetration. Pestic. Sci. 1980, 11(3), 367370. 
[14] Baker, E. A.; Bukovac, M. J., Characterization of Components of Plant Cuticles in Relation to Penetration of 2,4-D. Ann. Appl. Biol. 1971, 67(2), 243-253.

[15] Burghardt, M.; Friedmann, A.; Schreiber, L.; Riederer, M., Modelling the Effects of Alcohol Ethoxylates on Diffusion of Pesticides in the Cuticular Wax of Chenopodium Album Leaves. Pest. Manag. Sci. 2006, 62(2), 137-147.

[16] Riederer, M.; Burghardt, M.; Mayer, S.; Obermeier, H.; Schonherr, J., Sorption of Monodisperse Alcohol Ethoxylates and Their Effects on the Mobility of 2,4-D in Isolated Plant Cuticles. J. Agr. Food Chem. 1995, 43(4), 1067-1075.

[17] Schonherr, J.; Riederer, M.; Schreiber, L.; Bauer, H., Foliar Uptake of Pesticides and Its Activation by Adjuvants - Theories and Methods for Optimization. Pestic. Chem.: Adv. Int. Res., Dev., Legis., Pro. Int. Congr. Pestic. Chem., $7^{\text {th }}$. 1991, 237-253.

[18] Schreiber, L.; Bach, S.; Kirsch, T.; Knoll, D.; Schalz, K.; Riederer, M., A Simple Photometric Device Analysing Cuticular Transport Physiology: Surfactant Effect on Permeability of Isolated Cuticular Membranes of Prunus Laurocerasus L. J. Exp. Bot. 1995, 46(293), 1915-1921.

[19] Schreiber, L.; Riederer, M.; Schorn, K., Mobilities of Organic Compounds in Reconstituted Cuticular Wax of Barley Leaves: Effects of Monodisperse Alcohol Ethoxylates on Diffusion of Pentachlorophenol and Tetracosanoic Acid. Pestic Sci. 1996, 48(2), 117-124.

[20] Burghardt, M.; Schreiber, L.; Riederer, M., Enhancement of the Diffusion of Active Ingredients in Barley Leaf Cuticular Wax by Monodisperse Alcohol Ethoxylates. J. Agr. Food. Chem. 1998, 46(4), 1593-1602.

[21] Riederer, M.; Schonherr, J., Effects of Surfactants on Water Permeability of Isolated Plant Cuticles and on the Composition of Their Cuticular Waxes. Pestic. Sci. 1990, 29(1), 85-94.

[22] Pambou, E.; Li, Z.; Campana, M.; Hughes, A.; Clifton, L.; Gutfreund, P.; Foundling, J.; Bell, G.; Lu, J. R., Structural Features of Reconstituted Wheat Wax Films. J. R. Soc. Interface 2016, 13(120), 20160396.

[23] Koch, K.; Barthlott, W.; Koch, S.; Hommes, A.; Wandelt, K.; Mamdouh, W.; De-Feyter, S.; Broekmann, P., Structural Analysis of Wheat Wax (Triticum Aestivum, c.v. 'Naturastar' L.): from the Molecular Level to Three Dimensional Crystals. Planta 2006, 223(2), 258-270.

[24] Deswarte, F. E. I.; Clark, J. H.; Hardy, J. J. E.; Rose, P. M., The Fractionation of Valuable Wax Products from Wheat Straw Using $\mathrm{CO}_{2}$. Green Chem. 2006, 8(1), 39-42.

[25] Padia, F. N.; Yaseen, M.; Gore, B.; Rogers, S.; Bell, G.; Lu, J. R., Influence of Molecular Structure on the Size, Shape, and Nanostructure of Nonionic CnEm Surfactant Micelles. J. Phys. Chem. B. 2014, $118(1), 179-88$.

[26] Lu, J. R.; Li, Z. X.; Thomas, R. K.; Staples, E. J.; Tucker, I.; Penfold, J., Neutron Reflection from a Layer of Monododecyl Hexaethylene Glycol Adsorbed at the Air-Liquid Interface - the Configuration of the Ethylene-Glycol Chain. J. Phys. Chem. 1993, 97(30), 8012-8020.

[27] De Feijter, J. A.; Benjamins, J.; Veer, F. A., Ellipsometry as a Tool to Study the Adsorption Behavior of Synthetic and Biopolymers at the Air-Water Interface. Biopolymers 1978, 17(7), 1759-1772.

[28] Penfold, J.; Thomas, R. K., The Application of the Specular Reflection of Neutrons to the Study of Surfaces and Interfaces. J. Phys.: Condens. Matter. 1990, 2(6), 1369-1412.

[29] Daillant, J.; Gibaud, A., X-ray and Neutron Reflectivity: Principles and Applications; Springer: Berlin Heidelberg, 1999.

[30] Lu, J. R.; Thomas, R. K.; Penfold, J., Surfactant Layers at the Air/Water Interface: Structure and Composition. Adv. Colloid Interface Sci. 2000, 84(1-3), 143-304.

[31] Riederer, M.; Schneider, G., Comparative Study of the Composition of Waxes Extracted from Isolated Leaf Cuticles and from Whole Leaves of Citrus - Evidence for Selective Extraction. Physiol. Plant 1989, 77(3), 373-384.

[32] Clifton, L. A.; Skoda, M. W.; Le Brun, A. P.; Ciesielski, F.; Kuzmenko, I.; Holt, S. A.; Lakey, J. H., Effect of Divalent Cation Removal on the Structure of Gram-Negative Bacterial Outer Membrane Models. Langmuir 2015, 31(1), 404-12.

[33] Pambou, E.; Crewe, J.; Yaseen, M.; Padia, F. N.; Rogers, S.; Wang, D.; Xu, H.; Lu, J. R., Structural Features of Micelles of Zwitterionic Dodecyl-phosphocholine (C12PC) Surfactants Studied by SmallAngle Neutron Scattering. Langmuir 2015, 31(36), 9781-9.

[34] Bucknall, D. G.; Penfold, J.; Webster, J. R. P.; Zarbakhsh, A.; Richardson, R. M.; Rennie, A.; Higgins, J. S.; Jones, R. A. L.; Thomas, R. K.; Roser, S.; Dickinson, E., In SURF - a Second Generation 
Neutron Reflectometer, Proceedings of the Meetings ICANS-XIII and ESS-PM4 Volume I, Paul Scherrer Institut, Switzerland, 1995, 440.

[35] Parratt, L. G., Surface Studies of Solids by Total Reflection of X-Rays. Phys. Rev. 1954, 95(2), 359369.

[36] Abelès, F., La Théorie Générale des Couches Minces. J. Phys. Radium. 1950, 11(7), 307-309.

[37] Abélès, F., Recherches sur la Propagation des Ondes Electromagnétiques Sinusoïdales dans les Milieux Stratifiés-Application aux Couches Minces. Ann. Phys. EDP Sciences 1950, 12(5), 596-640.

[38] Hughes, A. RasCal 1.1.3 (Neutron and X-ray Reflectivity Data Analysis Tool), ISIS Spallation Neutron Source, Rutherford Appleton Laboratory, [Software] 2014.

[39] Hilfiker, J. N.; Singh, N.; Tiwald, T.; Convey, D.; Smith, S. M.; Baker, J. H.; Tompkins, H. G., Survey of Methods to Characterize Thin Absorbing Films with Spectroscopic Ellipsometry. Thin Solid Films 2008, 516(22), 7979-7989.

[40] Penfold, J.; Tucker, I.; Green, A.; Grainger, D.; Jones, C.; Ford, G.; Roberts, C.; Hubbard, J.; Petkov, J.; Thomas, R. K.; Grillo, I., Impact of Model Perfumes on Surfactant and Mixed Surfactant SelfAssembly. Langmuir 2008, 24(21), 12209-12220.

[41] Zulauf, M.; Weckstrom, K.; Hayter, J. B.; Degiorgio, V.; Corti, M., Neutron Scattering Study of Micelle Structure in Isotropic Aqueous-Solutions of Poly(Oxyethylene) Amphiphiles. J. Phys. Chem. 1985, 89(15), 3411-3417.

[42] Shi, L.; Tummala, N. R.; Striolo, A, C12E6 and SDS Surfactants Simulated at the Vacuum-Water Interface. Langmuir 2010, 26(8), 5462-5474.

[43] Tanford, C., Micelle Shape and Size. J. Phys. Chem. 1972, 76(21), 3020-3024.

[44] Shafer, W. E.; Bukovac, M. J., Studies on Octylphenoxy Surfactants .3. Sorption of Triton X-100 by Isolated Tomato Fruit Cuticles. Plant Physiol 1987, 85(4), 965-970.

[45] Stevens, P. J. G.; Bukovac, M. J., Studies on Octylphenoxy Surfactants. 2. Effects on Foliar Uptake and Translocation. Pestic. Sci. 1987, 20(1), 37-52.

[46] Zielinski, J. M.; Duda, J. L., Predicting Polymer Solvent Diffusion-Coefficients Using Free-Volume Theory. Aiche J. 1992, 38(3), 405-415. 
Table of contents graphic

Reversible - surfactant adsorption and penetration with little impact to wax film

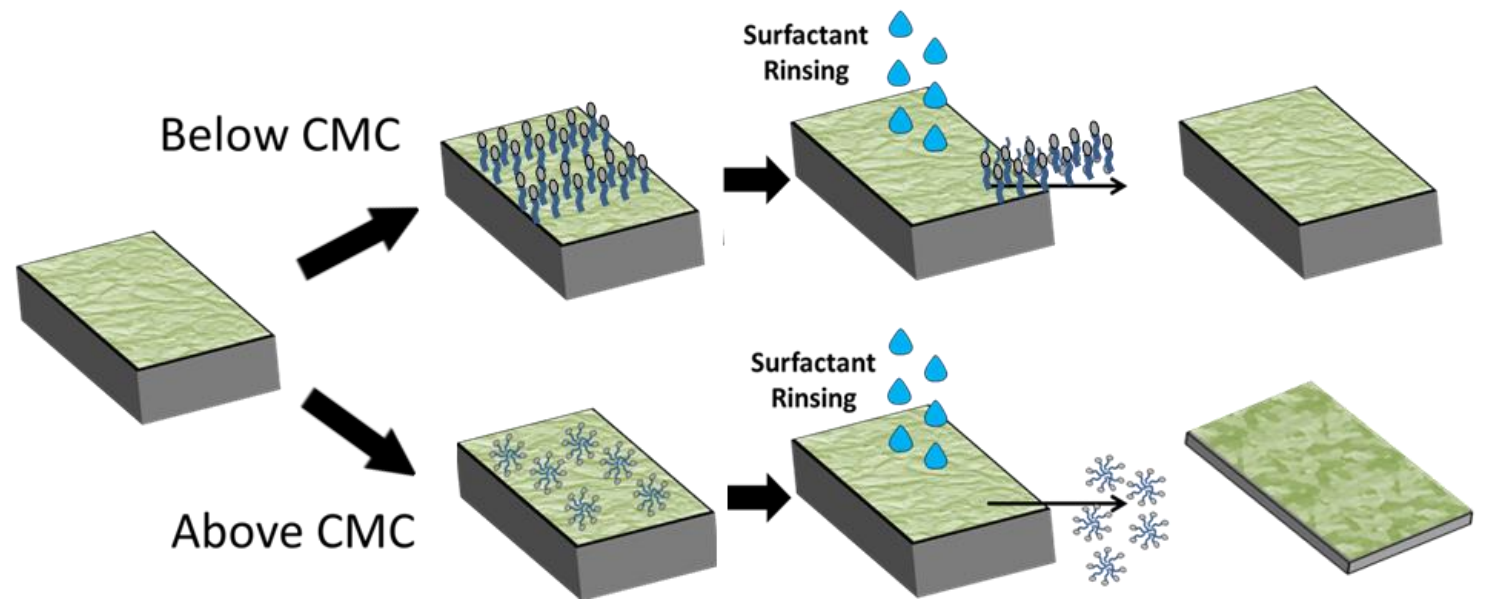

Irreversible-micellar action causes partial wax removal and structural damage 
Structural features of reconstituted cuticular wheat wax films upon

$$
\text { interaction with nonionic surfactant } \mathrm{C}_{12} \mathrm{E}_{6}
$$

Elias Pambou ${ }^{a}$, Xuzhi Hu ${ }^{a}$, Zongyi Li ${ }^{a}$, Mario Campana ${ }^{b}$,Arwel Hughes ${ }^{b}$, Peixun Li ${ }^{b}$, John R.P. Webster ${ }^{b}$, Gordon Bell', Jian R. Lu ${ }^{a^{*}}$

*E-mail:j.lu@manchester.ac.uk, Tel: (+44)-161-200-3926.

a Biological Physics Group, School of Physics and Astronomy, University of Manchester, Oxford Road, Manchester, M13 9PL, UK.

${ }^{\mathrm{b}}$ STFC ISIS Facility, Rutherford Appleton Laboratory, Didcot OX11 0QX, U.K.

${ }^{c}$ Syngenta, Jealott's Hill International Research Centre, Bracknell, Berkshire, RG42 6EY, UK.

Keywords: Wheat waxes, plant waxes, epicuticular wax films, neutron reflection, spectroscopic ellipsometry, nonionic surfactant

\section{A. List of scattering lengths and SLDs used in study}


Table S1: Scattering length, $b$ and scattering length densities (SLD, $\rho$ ), for commonly used materials in neutron reflectometry. The values were obtained from the 'Neutron scattering lengths and cross sections' database (NIST Centre for Neutron Research, www.ncnr.nist.gov).

\begin{tabular}{lll}
\hline Material & Scattering length, $b(\mathrm{fm})$ & Scattering length density, $\rho\left(\AA^{-2}\right)$ \\
\hline $\mathrm{H}_{2} \mathrm{O}$ & -1.68 & $-0.56 \times 10^{-6}$ \\
$\mathrm{D}_{2} \mathrm{O}$ & 19.15 & $6.35 \times 10^{-6}$ \\
silicon $(\mathrm{Si})$ & 4.15 & $2.07 \times 10^{-6}$ \\
silicon oxide $\left(\mathrm{SiO}_{2}\right)$ & 15.76 & $3.49 \times 10^{-6}$ \\
Air & $\mathrm{n} / \mathrm{a}$ & 0 \\
wheat waxes $[1,2]$ & $\mathrm{n} / \mathrm{a}$ & $-0.30 \times 10^{-6}$ \\
non-ionic surfactant, $\mathrm{h}-\mathrm{C}_{12} \mathrm{E}_{6}$ & 13.19 & $0.17 \times 10^{-6}$ \\
non-ionic surfactant, d- $\mathrm{C}_{12} \mathrm{E}_{6}$ & 273.48 & $3.61 \times 10^{-6}$ \\
\hline
\end{tabular}

The SLD of the main components in wheat waxes is $-0.3 \times 10^{-6} \AA^{-2}$ for long chain alcohols, $\sim 0$ $\AA^{-2}$ for long-chain fatty acids and $-0.6 \times 10^{-6} \AA^{-2}$ for long chain alkanes. Using the wax composition reported by Koch et al., ${ }^{\mathrm{S} 1}$ wheat waxes consist primarily of n-alkanols $\left(\mathrm{C}_{22-30}\right)$, esters $\left(\sim 10 \mathrm{~m} \% \mathrm{C}_{44}\right)$ and alkanes $\left(\mathrm{C}_{27-33}\right)$, with the $\mathrm{n}$-alkanol chain $\mathrm{C}_{28}(66 \mathrm{~m} \%)$ being the most prominent compound. In this study the SLD of the reconstituted wheat wax film was estimated by assuming it was made up of the two most prominent compounds of $86 \% \mathrm{C}_{28}$ alcohol and $14 \% \mathrm{C}_{44}$ ester to give an SLD value of $-0.3 \times 10^{-6} \AA^{-2}$. The minor components such as $C_{26}, 30$ alcohols, fatty acids and alkanes of different chain lengths have similar SLDs and their influence on the total SLD is small.

\section{B. Determination of the refractive index of reconstituted wheat wax by Abbe refractometry}

The refractive index-wavelength relationship of supercritical $\mathrm{CO}_{2}$ extracted cuticular wheat waxes were studied using an Abbe high-accuracy refractometer (Bellingham and Stanley, Abbe $60 / \mathrm{LR})$ with a refractive index range of 1.20-1.70 $( \pm 0.00004)$. The refractometer offers a 
measurement capability from $400-700 \mathrm{~nm}$.

Measurements were carried out by illuminating the sample with a spectral light source. The sample is placed between two prisms - measuring and illuminating. Light enters the sample from the illuminating prism and is refracted through the sample layer and into the measurement prism. The refractive index is determined by adjusting the viewing angle of a Vernier-scale-eye-piece used to observe the light transmitted through the prism until the refracted light could be observed. This appearance of refracted light is observed by the eye-piece as a boundary between a dark and light region of light and is defined by the critical angle of the sample measured.

The refractometer contains several compensating prisms to correct for any dispersion effects from the light source. This ensures that the observed light-dark boundary formed by refracted light has a sharp edge and that measurement accuracy is not compromised.

\section{$\underline{\text { Experimental setup and analysis }}$}

As refractive index is a function of wavelength a number of different spectral lamp sources were used to determine the sample's refractive index-wavelength relationship. Four spectral-lamp sources were used in this study; sodium, cadmium, helium and mercury corresponding to 12 measurements at various different emission lines.

Table S2: Wavelengths and emission lines of spectral sources used for refractometry (400-900 $\mathrm{nm})$.

\begin{tabular}{lll}
\hline Source & Emission line & Wavelength, $\mathrm{nm}(\lambda)$ \\
\hline \multirow{3}{*}{ Mercury (HG) } & h-line (violet) & 404.7 \\
& g-line (blue) & 435.8 \\
& e-line (green) & 546.1 \\
& yellow-orange & 579.1 \\
\hline \multirow{2}{*}{ Cadmium (Cd) } & Blue & 467.8 \\
& f'-line (blue) & 480.0
\end{tabular}




\begin{tabular}{lll}
\hline & & \\
& c'-line (red) & 643.8 \\
& Green & 508.6 \\
\hline \multirow{3}{*}{ Helium $(\mathrm{He})$} & d-line (yellow) & 587.6 \\
& Red & 667.8 \\
& r-line (red) & 706.5 \\
\hline Sodium $(\mathrm{Na})$ & $\mathrm{d}_{1}$-line (yellow) & 589.6 \\
\hline
\end{tabular}

The refractive index of the material was calculated from a corresponding Abbe scale and temperature readings read off the refractometer eye-piece by using the accompanying Abbe utility software supplied with the instrument. Temperature effects are automatically accounted for by the software, using a well-defined temperature-refractive index relationship for edible oils/waxes; $-0.0004 /{ }^{\circ} \mathrm{C}$.

Samples for refractometry measurements were prepared by coating a film of approximately 0.25 mm directly onto the quartz measurement prism. The soft wax films were prepared by curing the sample in a press between sheets of aluminium foil and then applying the exposed surface of the sample onto a cleaned prism surface.

The polished surfaces of the illumination and measurement prisms were cleaned using distilled water and dried with a lint-free tissue before measurement. After measurement, samples are removed from the measurement prism using a suitable solvent, ethanol in this case, before wiping again with water and lint-free tissue. Care was taken to avoid scratching the prism surface as this reduces measurement quality. After cleaning, a calibration adjustment must be carried out again prior to any future study to check that the instrument is reading correctly by using a silicon test piece of well-defined refractive index.

\section{$\underline{\text { Results }}$}

The refractive index-wavelength relationship of reconstituted wheat waxes obtained using Abbe refractometry measurements are shown below. The refractive index-wavelength relationship, $n(\lambda)$ can be seen to correspond well to the Cauchy empirical relationship $\left(n(\lambda)=A+B / \lambda^{2}+\right.$ $\left.C / \lambda^{4} \ldots\right)$ used to represent refractive index distributions over the visible light range (Figure $\mathrm{S} 1$ ). 
By applying a best fit in the form of a Cauchy formula to the data, we obtain a best-fitting relation of $1.45+0.01 / \lambda^{2}$. At the Sodium $(\mathrm{Na}) \mathrm{d}$-line $(589.0 \mathrm{~nm})$ the refractive index for the bulk reconstituted wax sample was determined to be 1.478 , with errors of \pm 0.005 .

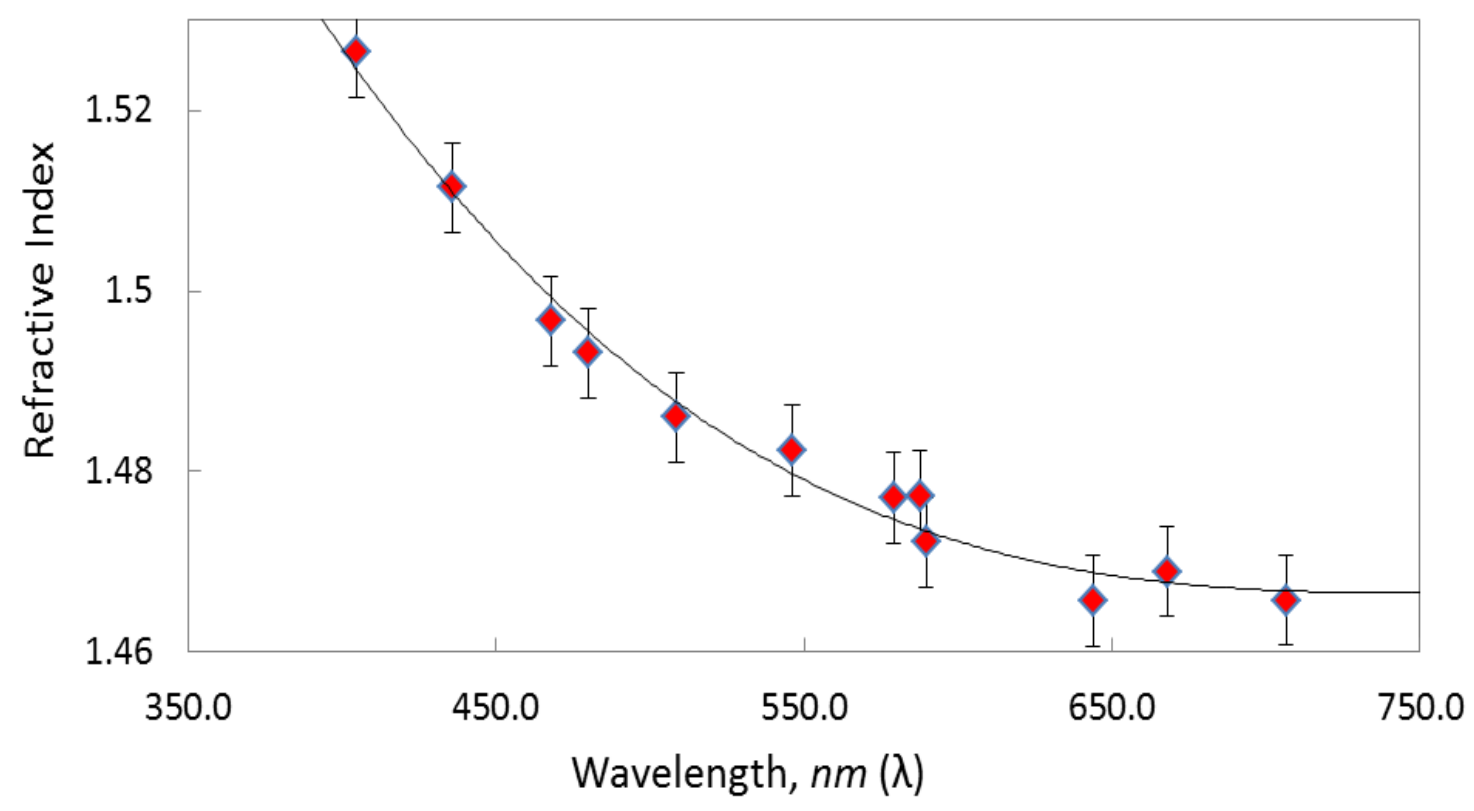

Figure S1. Refractive index vs wavelength, $\lambda$ for SC extracted wheat wax.

\section{Hughes Error function model}

The Hughes error function model provides a representative description of the interfacial density distribution versus interfacial distance $z$ as measured by NR. ${ }^{\mathrm{S}, \mathrm{S3}}$ Using this approach, a more comprehensive model fitting requiring fewer variable parameters than the traditional multilayer approaches to NR fitting can be obtained to describe the film structure. Equation (S1) describes the volume fraction distribution profile, $\phi_{n}(z)$ of each modelled layer, $n$, while the sum of all the layer distributions, $\phi(z)$, is determined to produce a single profile describing the whole system as 
a function of $z$ (Equation (S2)), with an example of the total distribution profile being presented in Figure 5 in the manuscript. Likewise, Equation (S3) describes the total scattering length density (SLD) distribution, $\rho(z)$, by taking into account the SLD contribution from the material, $\sum_{i=0}^{n} \phi_{i}(z) \rho_{i}$, and from the water, $[1-\phi(z)] \rho_{\text {water }}$.

$$
\begin{gathered}
\phi_{n}(z)=\varphi_{n} \frac{h}{2}(\operatorname{erf}(a)-\operatorname{erf}(b)), \\
\phi(z)=\phi_{0}(z)+\phi_{1}(z)+\cdots \phi_{n}(z), \\
\rho(z)=\left[\phi_{0}(z) \rho_{0}+\phi_{1}(z) \rho_{1}+\cdots \phi_{n}(z) \rho_{n}\right]+[1-\phi(z)] \rho_{\text {water }},
\end{gathered}
$$

where $z$ ranges from 0 to $\infty, h$ is the height of the step function (normalized to 1) and $\operatorname{erf}(a)$ and $e r f(b)$ are the 'Gauss' error functions as defined in Equations (S4) and (S5). $\varphi_{n}$ is a scale factor term which represents the coverage of the modelled layer assuming a uniform slab with a defined SLD, and $\rho_{0}, \rho_{1}$ and $\rho_{n}$ are the SLD for layer 0 , layer 1 and layer $n$, respectively.

With respect to the 2-layer wax film model as schematically shown in Figure (S2), $\phi_{0}(z)$ refers to the volume fraction distribution of the underlying silicon oxide layer, $\phi_{1}(z)$ and $\phi_{2}(z)$ being the volume fraction distributions of the two wax layers, respectively. $\rho_{0}$ would therefore represent the SLD of the silicon oxide $\left(3.42 \times 10^{-6} \AA^{-2}\right)$, and $\rho_{1}$ and $\rho_{2}$ the SLD of the two wax film layers $\left(-0.30 \times 10^{-6} \AA^{-2}\right)$.

In modelling the neutron reflection data, the interfacial density profiles of the layers are described by the difference between the two error functions that represent the integrals over Gaussian distributions. Each of these error functions (Equation (S1)) has two spatial dimension parameters that describe the shape and location of the layer. These parameters are represented schematically by Figure S2 for a 2-layer wax film model.

$$
\begin{gathered}
\operatorname{erf}(x)=\frac{2}{\sqrt{\pi}} \int_{0}^{x} e^{-z^{2}} d z, \\
a(z)=\frac{z-\tau_{a}}{\sqrt{2} \sigma_{a}}, \quad b(z)=\frac{z-\tau_{b}}{\sqrt{2} \sigma_{b}} .
\end{gathered}
$$


where $a(z)$ and $b(z)$ together describe the density distribution profiles of a modelled layer. Here, $z$ is the distance away from the substrate interface (the surface of layer 0 ) while positions $\tau_{a}, \tau_{b}$ describe the interfacial distances from the substrate at the bottom and top of the layer, respectively. Thus, the difference between $\tau_{a, n}$ and $\tau_{b, n}$ is the width of the distribution of layer $\mathrm{n}$ with thickness $\tau_{n}$ and $\sigma_{a} \& \sigma_{b}$ are the decay (roughness) parameters at the start (bottom) and end (top) of the layer which define the shape of the error function at each side. Each layer is modelled such that $\sigma_{a}$ of one layer is equal to the $\sigma_{b}$ of the previous layer such that $\sigma_{a, n}=\sigma_{b, n-1}$ (see Figure S2). The symmetry at the interface of each layer simplifies the model as only one value of $\sigma$ is required to describe each layer. As explained earlier, Thus, in the Hughes model each layer is characterized by 3 main parameters, $\tau_{n}, \sigma_{n}, \varphi_{n}$.

With respect to the 2-layer wax film model, the 3 parameters describing the two wax film layers are represented in Figure S2 and the best-fitted parameters are listed in Tables S3 \& S4. For all fittings the $\mathrm{SiO}_{2}$ layer $(n=0)$ had fixed thickness and decay parameter $\tau_{0}, \sigma_{0}$, of $15 \AA$ and $2 \AA$, with $\varphi_{0}=1$. The Hughes error function model was used to fit the experimentally measured NR data in the same way as fitting any standard stratified film via the Abeles layer method (described by Equations (S6-S9)). This means that the Heaviside model could be used with standard fitting software. In general, the SLD profile constructed from the material's volume fraction distribution is sliced into a discrete series of homogeneous slabs characterised by their SLDs and thicknesses, before being resampled and stitched together using the standard Abeles layer method to produce the fitted NR model. For a discrete series of slabs of $i$ layers, each of uniform thickness, $\tau_{i}$ and scattering length density $\rho_{i}$, we obtain the wave vector, $k_{i}$ :

$$
k_{i}=\sqrt{k_{\mathrm{s}}^{2}-4 \pi\left(\rho_{i}-\rho_{\mathrm{s}}\right)}
$$

where $k_{\mathrm{s}}$ and $\rho_{\mathrm{s}}$ are the wave vector and scattering length density of the underlying silicon substrate that the neutrons travel through. Thus, through the Fresnel refraction coefficient describing the reflected neutron amplitudes between two adjacent layers we obtain: 


$$
r_{i, i+1}=\frac{n_{i} \sin \theta_{i}-n_{i+1} \sin \theta_{i+1}}{n_{i} \sin \theta_{i}+n_{i+1} \sin \theta_{i+1}}=\frac{k_{i}-k_{i+1}}{k_{i}+k_{i+1}}
$$

The general solution to the optical matrix calculation (the Abeles matrix) describing the reflectivity from multiple slab layers as a function of momentum transfer is described by the optical matrix formula which is a product of the characteristic matrices for each individual layer from which reflectivity, $R$ is calculated:

$$
\begin{gathered}
\boldsymbol{M}=\prod_{0}^{i}\left[\begin{array}{cc}
\exp \left(k_{i} \tau_{i}\right) & r_{i} \exp \left(k_{i} \tau_{i}\right) \\
r_{i} \exp \left(-k_{i} \tau_{i}\right) & \exp \left(-k_{i} \tau_{i}\right)
\end{array}\right] . \\
R=\left|\frac{M_{00}}{M_{10}}\right|^{2}
\end{gathered}
$$

The 2-layer 'Hughes function' used to describe the material's volume fraction and scattering density (SLD) distributions in this study offered a good description of the underlying cuticular film and crystalline surface region as observed in reconstituted wheat wax film, thus providing a simpler alternative to the standard Abeles layer method based on the optical matrix formula.

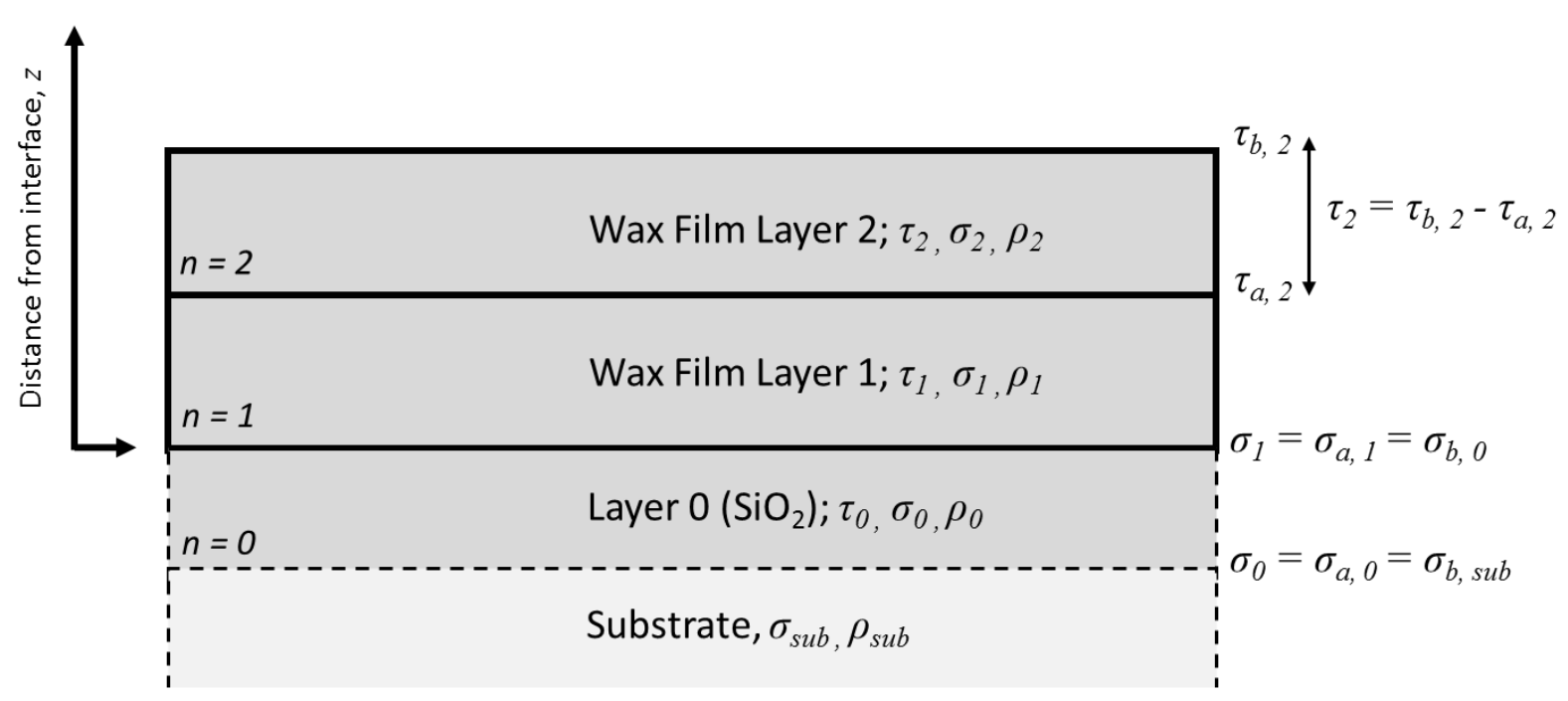

Figure S2. Schematic of the 2-layer wax film model outlining the spatial parameters $\tau_{n}$ and $\sigma_{n}$ that describe the distribution profiles of each modelled layer, $n$, where $n=1,2$. The $\mathrm{SiO}_{2}$ layer had a fixed thickness and decay parameter $\tau_{0}, \sigma_{0}$, of $15 \AA$ and $2 \AA$, respectively and thus $\sigma_{\text {sub }}=$ $2 \AA$ A. These parameters were fixed for all NR measurements. 


\section{Neutron reflectometry: Full set of results}

\section{Interaction of reconstituted wheat wax with fully-protonated $h_{C_{12}} \mathrm{E}_{6}$ surfactant}

Table S3: Structural parameters obtained from solid-liquid NR measurements of the interaction of the fully protonated $\mathrm{hC}_{12} \mathrm{E}_{6}$ with model wax films. Surfactants of increasing concentration were deposited and subsequently rinsed off the wax film surface. Measurements were obtained at 0.05 CMC, 0.2 CMC, 0.5 CMC, $1 \mathrm{CMC}$, and $5 \mathrm{CMC}$ as well as the rinse cycles carried out between measurements.

\begin{tabular}{|c|c|c|c|c|c|c|c|}
\hline \multirow[b]{2}{*}{$\begin{array}{c}\text { Sample } \\
\text { (Wheat wax interaction } \\
\text { w/ fully-protonated h- } \\
\mathbf{C}_{\mathbf{1 2}} \mathbf{E}_{\mathbf{6}} \text { ) }\end{array}$} & \multirow[b]{2}{*}{$\begin{array}{c}\text { Coverage, } \\
\text { film layer, } \\
\varphi_{1}, \\
( \pm 0.05)\end{array}$} & \multirow[b]{2}{*}{$\begin{array}{l}\text { Coverage, } \\
\text { extrusion } \\
\text { layer, } \varphi_{2}, \\
\quad( \pm 0.05)\end{array}$} & \multicolumn{2}{|c|}{ Film Layer } & \multicolumn{2}{|c|}{ Extrusion Layer } & \multirow[b]{2}{*}{$\begin{array}{l}\text { Combi } \\
\text { ned } \\
\text { Reduced } \\
\text { Chi-Sq. }\end{array}$} \\
\hline & & & $\begin{array}{l}\text { Thickness, } \\
\tau_{1}, \AA \\
( \pm 3)\end{array}$ & $\begin{array}{c}\text { Decay } \\
\text { Parameter, } \\
\sigma_{1}, \AA \\
( \pm 2)\end{array}$ & $\begin{array}{l}\text { Thicknes } \\
\mathrm{s}, \tau_{2}, \AA \\
( \pm 5)\end{array}$ & $\begin{array}{c}\text { Decay } \\
\text { Parameter, } \\
\sigma_{2}, \AA \\
( \pm 6) \\
\end{array}$ & \\
\hline $\mathrm{Si} /$ Wheat/ $\mathrm{D}_{2} \mathrm{O}$ & 0.73 & 0.24 & 65 & 20 & 125 & 105 & 3.71 \\
\hline $\begin{array}{c}\text { Si/Wheat } / 0.05 \text { CMC h- } \\
\quad C_{12} \mathrm{E}_{6} / \mathrm{D}_{2} \mathrm{O}\end{array}$ & 0.78 & 0.27 & 63 & 22 & 125 & 105 & 4.02 \\
\hline $\begin{array}{l}\text { Post } 0.05 \text { CMC Rinse } \\
\text { cycle }\end{array}$ & 0.77 & 0.24 & 64 & 25 & 125 & 105 & 2.36 \\
\hline $\begin{array}{l}\text { Si/Wheat/0.2 CMC h- } \\
\quad \mathrm{C}_{12} \mathrm{E}_{6} / \mathrm{D}_{2} \mathrm{O}\end{array}$ & 0.85 & 0.28 & 66 & 28 & 125 & 105 & 2.43 \\
\hline
\end{tabular}




\begin{tabular}{|c|c|c|c|c|c|c|c|}
\hline $\begin{array}{l}\text { Post } 0.2 \text { CMC Rinse } \\
\text { cycle }\end{array}$ & 0.79 & 0.22 & 64 & 26 & 125 & 105 & 1.68 \\
\hline $\begin{array}{l}\mathrm{Si} / \text { Wheat/0.5 CMC h- } \\
\quad \mathrm{C}_{12} \mathrm{E}_{6} / \mathrm{D}_{2} \mathrm{O}\end{array}$ & 0.85 & 0.26 & 66 & 29 & 125 & 105 & 1.88 \\
\hline $\begin{array}{l}\text { Post } 0.5 \text { CMC Rinse } \\
\text { cycle }\end{array}$ & 0.78 & 0.22 & 66 & 26 & 125 & 105 & 1.58 \\
\hline $\begin{array}{l}\mathrm{Si} / \text { Wheat/1 CMC h- } \\
\quad \mathrm{C}_{12} \mathrm{E}_{6} / \mathrm{D}_{2} \mathrm{O}\end{array}$ & 0.88 & 0.26 & 70 & 40 & 125 & 105 & 1.76 \\
\hline $\begin{array}{l}\text { Post } 1 \text { CMC Rinse } \\
\text { cycle }\end{array}$ & 0.69 & 0.15 & 68 & 23 & 125 & 101 & 2.47 \\
\hline $\begin{array}{l}\mathrm{Si} / \text { Wheat } / 5 \mathrm{CMC} \text { h- } \\
\quad \mathrm{C}_{12} \mathrm{E}_{6} / \mathrm{D}_{2} \mathrm{O}\end{array}$ & 0.55 & 0.15 & 34 & 12 & 103 & 93 & 2.81 \\
\hline $\begin{array}{l}\text { Post } 5 \text { CMC Rinse } \\
\text { cycle }\end{array}$ & 0.15 & 0.14 & 31 & 9 & 111 & 70 & 0.97 \\
\hline
\end{tabular}

A flat background of 6 to $8 \times 10^{-6}$ was applied to all fittings.

Figures S3 - S13: NR plots of the interaction of the fully protonated $\mathrm{hC}_{12} \mathrm{E}_{6}$ with model reconstituted wheat wax films. Measurements were obtained with no surfactant, and at 0.05 CMC, $0.2 \mathrm{CMC}, 0.5 \mathrm{CMC}, 1 \mathrm{CMC}$, and $5 \mathrm{CMC} \mathrm{C}_{12} \mathrm{E}_{6}$ as well as the rinse cycles carried out between measurements.

Figures S3 - S5:

- $\mathrm{S} 3-\mathrm{Si} / \mathrm{Wheat}$ wax $/ \mathrm{D}_{2} \mathrm{O}$

- $\mathrm{S} 4$ - Wheat wax/ $0.05 \mathrm{hC}_{12} \mathrm{E}_{6} / \mathrm{D}_{2} \mathrm{O}$

- $\mathrm{S} 5$ - Wheat wax/ $0.05 \mathrm{hC}_{12} \mathrm{E}_{6}$ Rinse / $\mathrm{D}_{2} \mathrm{O}$ 


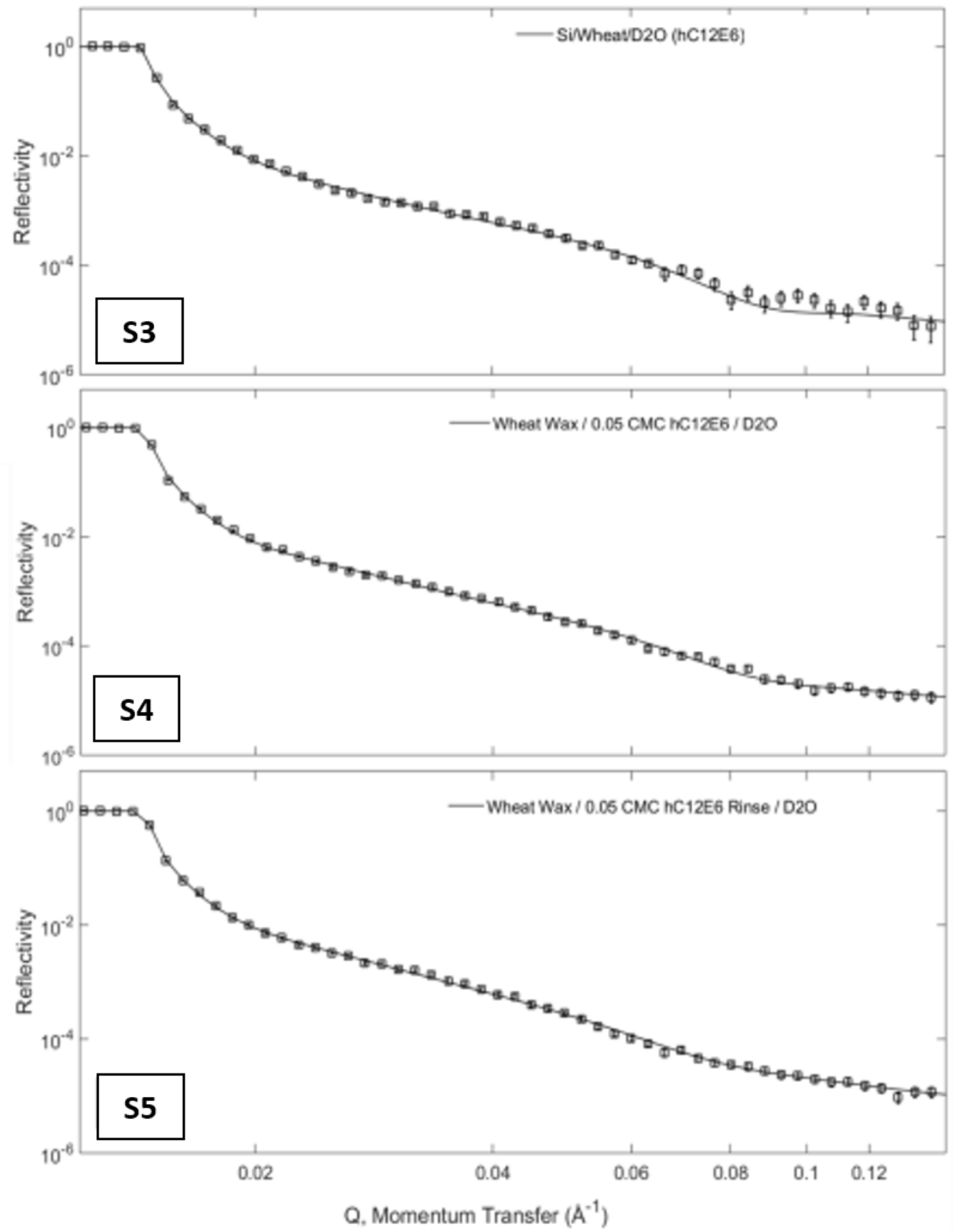

Figures S6 - S9:

- $\mathrm{S} 6$ - Wheat wax/ $0.2 \mathrm{hC}_{12} \mathrm{E}_{6} / \mathrm{D}_{2} \mathrm{O}$

- $\mathrm{S} 7$ - Wheat wax/ $0.2 \mathrm{hC}_{12} \mathrm{E}_{6}$ Rinse $/ \mathrm{D}_{2} \mathrm{O}$

- $\mathrm{S} 8$ - Wheat wax/ $0.5 \mathrm{hC}_{12} \mathrm{E}_{6} / \mathrm{D}_{2} \mathrm{O}$

- $\mathrm{S} 9$ - Wheat wax/ $0.5 \mathrm{hC}_{12} \mathrm{E}_{6}$ Rinse / $\mathrm{D}_{2} \mathrm{O}$ 

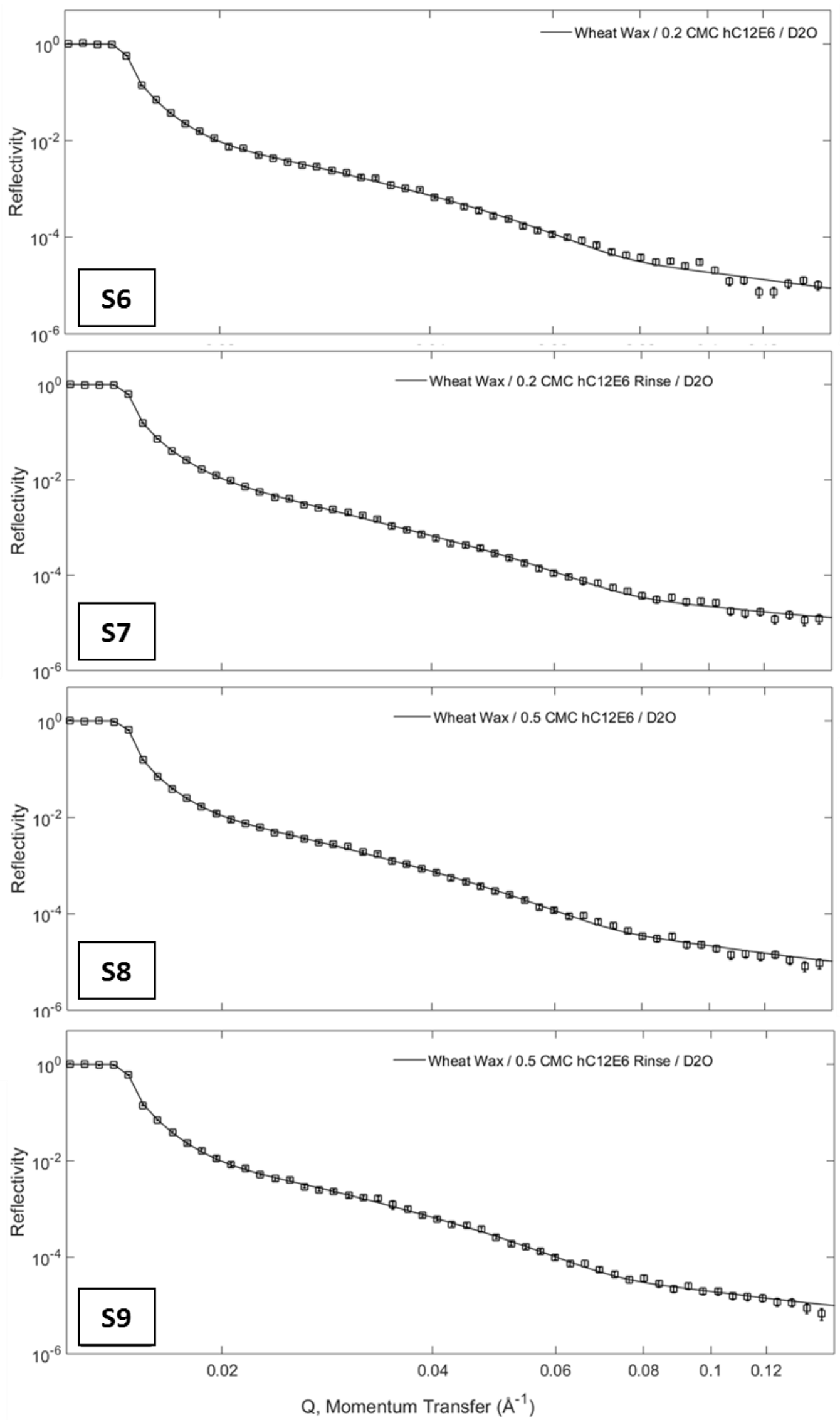

Figures S10 -

$\underline{\text { S13: }}$

- $\mathrm{S} 10-$

Wheat wax/ $1 \mathrm{hC}_{12} \mathrm{E}_{6} / \mathrm{D}_{2} \mathrm{O}$

- $\mathrm{S} 11$ - Wheat wax/ $1 \mathrm{hC}_{12} \mathrm{E}_{6}$ Rinse / $\mathrm{D}_{2} \mathrm{O}$

- $\mathrm{S} 12$ - Wheat wax/ $5 \mathrm{hC}_{12} \mathrm{E}_{6} / \mathrm{D}_{2} \mathrm{O}$ 
- $\mathrm{S} 13$ - Wheat wax $/ 5 \mathrm{hC}_{12} \mathrm{E}_{6}$ Rinse / $\mathrm{D}_{2} \mathrm{O}$
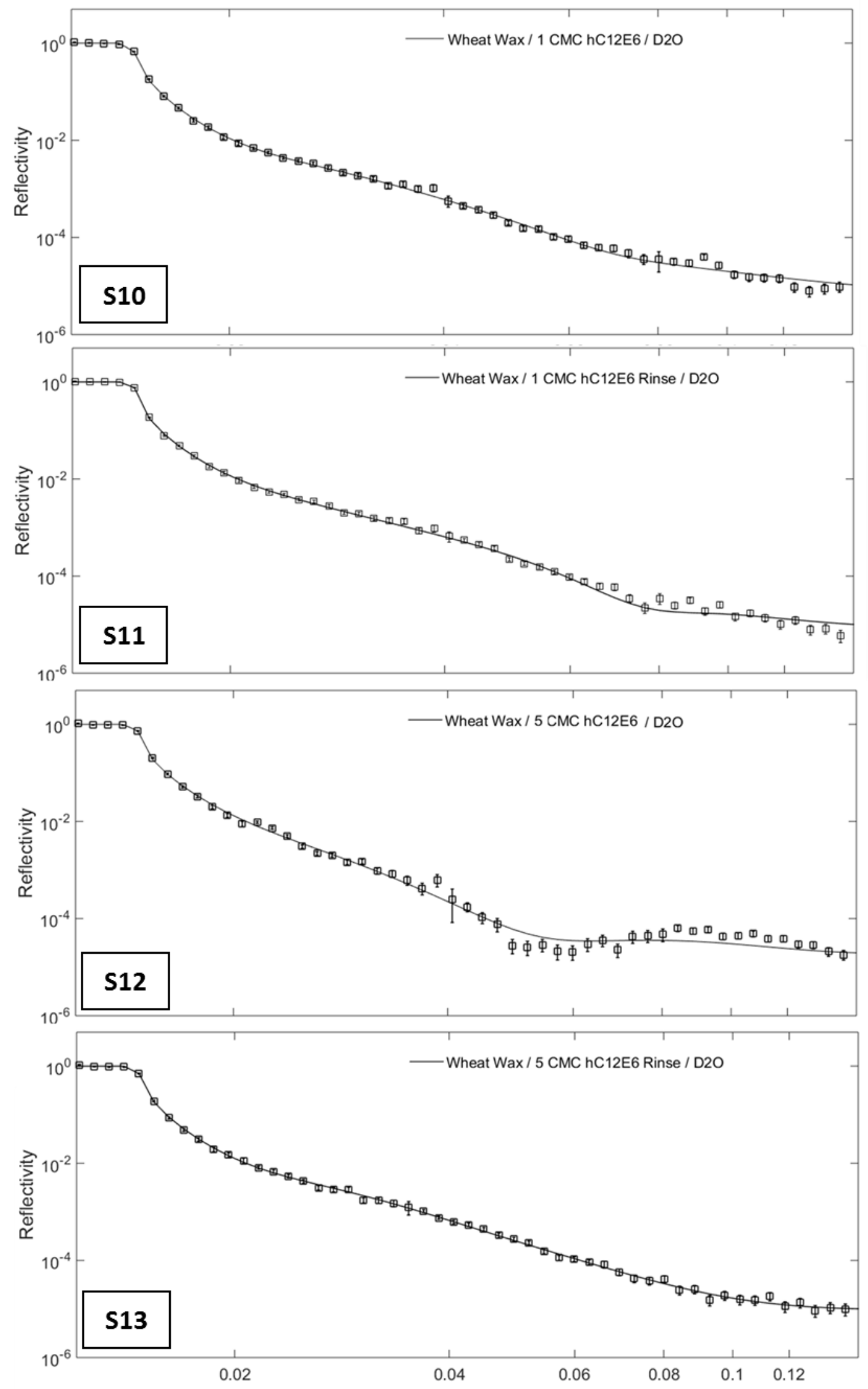

Q. Momentum Transfer $\left(\AA^{-1}\right)$

Interaction of reconstituted

wheat wax with chain-deuterated (d-) $\mathrm{C}_{12} \mathrm{E}_{6}$ surfactant 
Table S4: Structural parameters obtained for solid-liquid NR measurements of the interaction of the chain-deuterated $\mathrm{dC}_{12} \mathrm{E}_{6}$ with model reconstituted wheat wax films. Surfactants of increasing concentration were deposited and subsequently rinsed off the wax film surface. Measurements were obtained at $0.05 \mathrm{CMC}, 0.2 \mathrm{CMC}, 0.5 \mathrm{CMC}, 1 \mathrm{CMC}$, and $5 \mathrm{CMC}$ as well as the rinse cycles carried out between measurements. $(*=$ Poor fit $)$.

\begin{tabular}{|c|c|c|c|c|c|c|c|}
\hline \multirow[b]{2}{*}{$\begin{array}{c}\text { Sample } \\
\text { (Wheat wax } \\
\text { interaction w/ chain- } \\
\text { deuterated d- } \mathbf{C}_{\mathbf{1 2}} \mathbf{E}_{\mathbf{6}} \text { ) }\end{array}$} & \multirow[b]{2}{*}{$\begin{array}{c}\text { Coverage, } \\
\text { film layer, } \\
\qquad \varphi_{1} \\
( \pm 0.05)\end{array}$} & \multirow[b]{2}{*}{$\begin{array}{l}\text { Coverage, } \\
\text { extrusion } \\
\text { layer, } \varphi_{2}, \\
\quad( \pm 0.05)\end{array}$} & \multicolumn{2}{|c|}{ Film Layer } & \multicolumn{2}{|c|}{ Extrusion Layer } & \multirow[b]{2}{*}{$\begin{array}{l}\text { Combin } \\
\text { ed } \\
\text { Reduced } \\
\text { Chi-Sq. }\end{array}$} \\
\hline & & & $\begin{array}{l}\text { Thickness } \\
, \tau_{l}, \AA \\
( \pm 3)\end{array}$ & $\begin{array}{c}\text { Decay } \\
\text { Parameter, } \\
\sigma_{1}, \AA \\
( \pm 2) \\
\end{array}$ & $\begin{array}{c}\text { Thicknes } \\
\mathrm{s}, \tau_{2}, \AA \\
( \pm 5)\end{array}$ & $\begin{array}{c}\text { Decay } \\
\text { Parameter, } \\
\sigma_{2}, \AA \\
( \pm 4) \\
\end{array}$ & \\
\hline $\mathrm{Si} /$ Wheat $/ \mathrm{D}_{2} \mathrm{O}$ & 0.83 & 0.18 & 58 & 24 & 150 & 110 & 1.60 \\
\hline $\begin{array}{c}* \mathrm{Si} / \text { Wheat } / 0.05 \mathrm{CMC} \\
\mathrm{d}-\mathrm{C}_{12} \mathrm{E}_{6} / \mathrm{D}_{2} \mathrm{O}\end{array}$ & 0.90 & 0.18 & 55 & 30 & 150 & 110 & 1.50 \\
\hline $\begin{array}{l}\text { Post } 0.05 \text { CMC Rinse } \\
\text { cycle }\end{array}$ & 0.82 & 0.17 & 60 & 26 & 150 & 110 & 1.96 \\
\hline $\begin{array}{l}\text { Si/Wheat/0.2 CMC d- } \\
\quad \mathrm{C}_{12} \mathrm{E}_{6} / \mathrm{D}_{2} \mathrm{O}\end{array}$ & 0.81 & 0.14 & 69 & 28 & 150 & 110 & 3.11 \\
\hline $\begin{array}{l}\text { Post } 0.2 \text { CMC Rinse } \\
\text { cycle }\end{array}$ & 0.87 & 0.14 & 64 & 30 & 150 & 110 & 1.91 \\
\hline $\begin{array}{l}\text { Si/Wheat/0.5 CMC d- } \\
\quad \mathrm{C}_{12} \mathrm{E}_{6} / \mathrm{D}_{2} \mathrm{O}\end{array}$ & 0.84 & 0.12 & 71 & 33 & 150 & 110 & 2.00 \\
\hline $\begin{array}{c}\text { Post } 0.5 \text { CMC Rinse } \\
\text { cycle }\end{array}$ & 0.87 & 0.13 & 65 & 31 & 150 & 110 & 1.48 \\
\hline $\begin{array}{l}* \mathrm{Si} / \text { Wheat/1 CMC d- } \\
\mathrm{C}_{12} \mathrm{E}_{6} / \mathrm{D}_{2} \mathrm{O}\end{array}$ & 0.90 & 0.11 & 65 & 42 & 150 & 110 & 7.63 \\
\hline $\begin{array}{l}* \text { Post } 1 \text { CMC Rinse } \\
\text { cycle }\end{array}$ & 0.75 & 0.10 & 46 & 12 & 141 & 94 & 7.40 \\
\hline $\begin{array}{l}\text { Si/Wheat } / 5 \text { CMC d- } \\
\mathrm{C}_{12} \mathrm{E}_{6} / \mathrm{D}_{2} \mathrm{O}\end{array}$ & 0.72 & 0.05 & 33 & 14 & 160 & 91 & 2.20 \\
\hline
\end{tabular}

A flat background of 6 to $8 \times 10^{-6}$ was applied to all fittings

Figures S14 - S23: NR plots of the interaction of the chain-deuterateddC ${ }_{12} \mathrm{E}_{6}$ with model films formed from reconstituted wheat waxes. Measurements were obtained with no surfactant, and at 
0.05 CMC, 0.2 CMC, 0.5 CMC, $1 \mathrm{CMC}$, and $5 \mathrm{CMC} \mathrm{C}_{12} \mathrm{E}_{6}$ as well as the rinse cycles carried out between measurements.

Figures S14-S16:

- $\mathrm{S} 14-\mathrm{Si} / \mathrm{Wheat} / \mathrm{D}_{2} \mathrm{O}$

- $\mathrm{S} 15$ - Wheat wax/ $0.05 \mathrm{dC}_{12} \mathrm{E}_{6} / \mathrm{D}_{2} \mathrm{O}$

- $\mathrm{S} 16$ - Wheat wax/ $0.05 \mathrm{dC}_{12} \mathrm{E}_{6}$ Rinse / $\mathrm{D}_{2} \mathrm{O}$
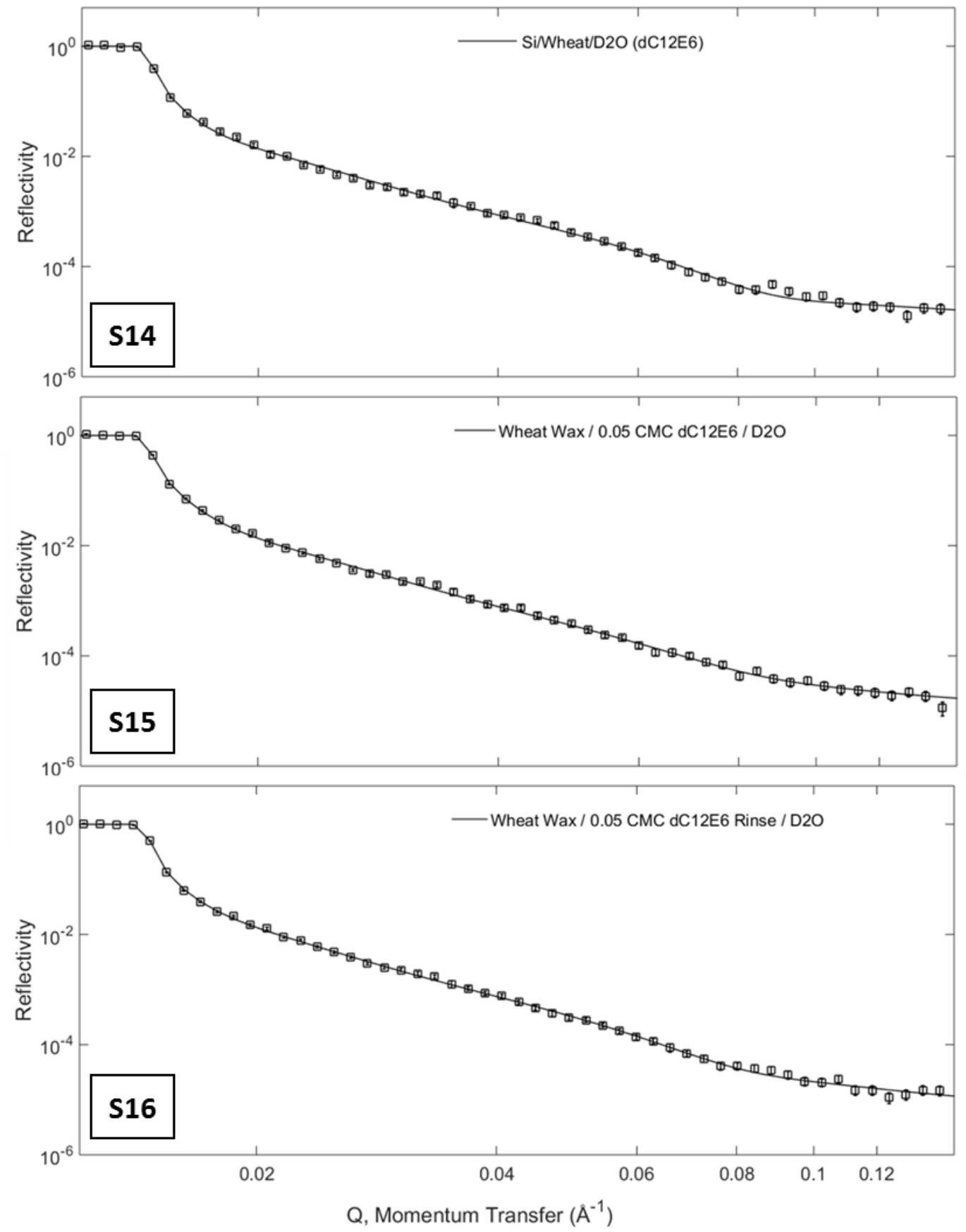

Figures S17 - S20:

- $\mathrm{S} 17$ - Wheat wax/ $0.2 \mathrm{dC}_{12} \mathrm{E}_{6} / \mathrm{D}_{2} \mathrm{O}$

- $\mathrm{S} 18$ - Wheat wax/ $0.2 \mathrm{dC}_{12} \mathrm{E}_{6}$ Rinse / $\mathrm{D}_{2} \mathrm{O}$ 
- $\mathrm{S} 19$ - Wheat wax/ $0.5 \mathrm{dC}_{12} \mathrm{E}_{6} / \mathrm{D}_{2} \mathrm{O}$

- $\mathrm{S} 20$ - Wheat wax/ $0.5 \mathrm{dC}_{12} \mathrm{E}_{6}$ Rinse / $\mathrm{D}_{2} \mathrm{O}$
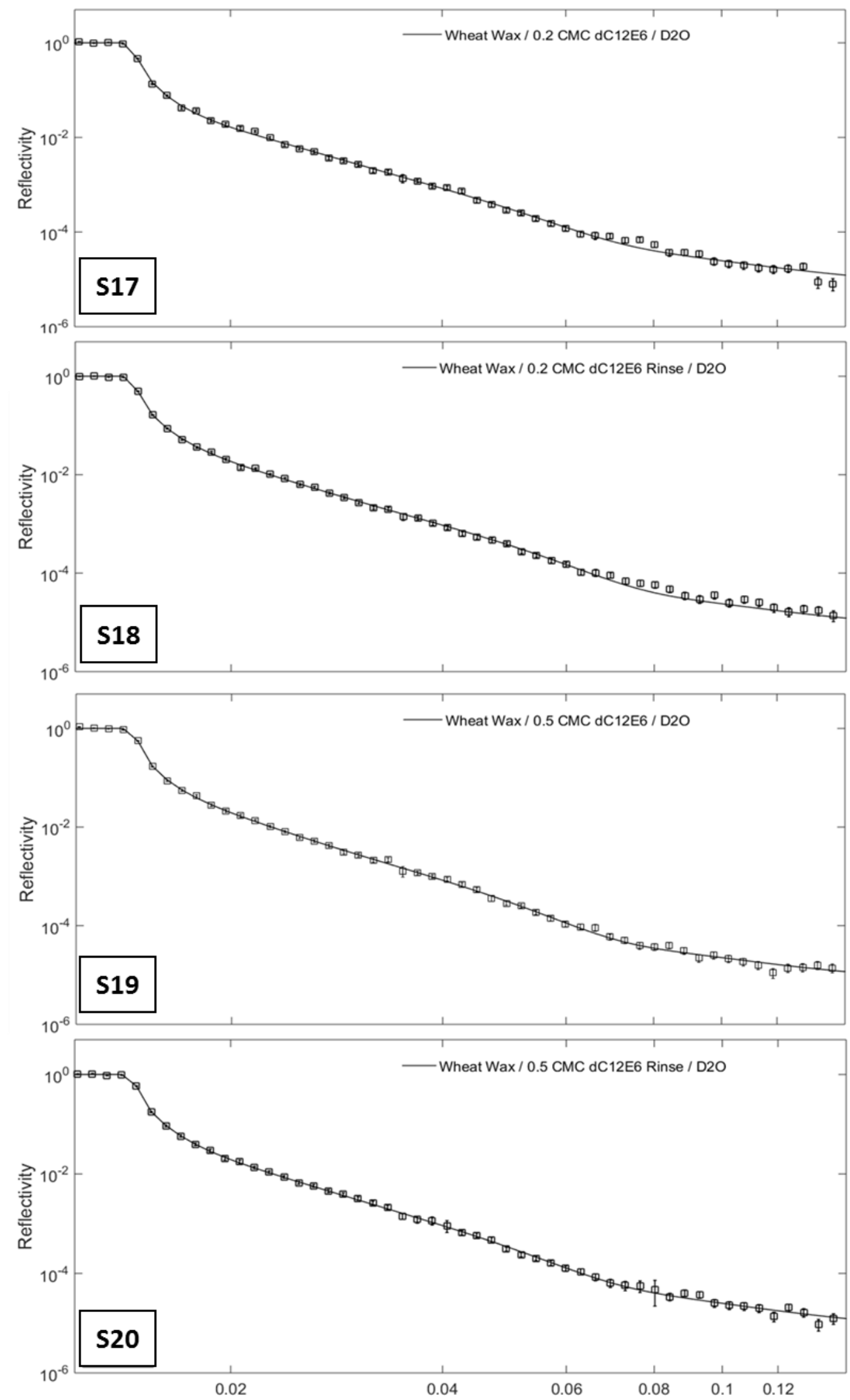

Q, Momentum Transfer $\left(\AA^{-1}\right)$ 
- $\mathrm{S} 21$ - Wheat wax/ $1 \mathrm{dC}_{12} \mathrm{E}_{6} / \mathrm{D}_{2} \mathrm{O}$

- $\mathrm{S} 22$ - Wheat wax/ $1 \mathrm{dC}_{12} \mathrm{E}_{6}$ Rinse $/ \mathrm{D}_{2} \mathrm{O}$

- $\mathrm{S} 23$ - Wheat wax/ $5 \mathrm{dC}_{12} \mathrm{E}_{6} / \mathrm{D}_{2} \mathrm{O}$
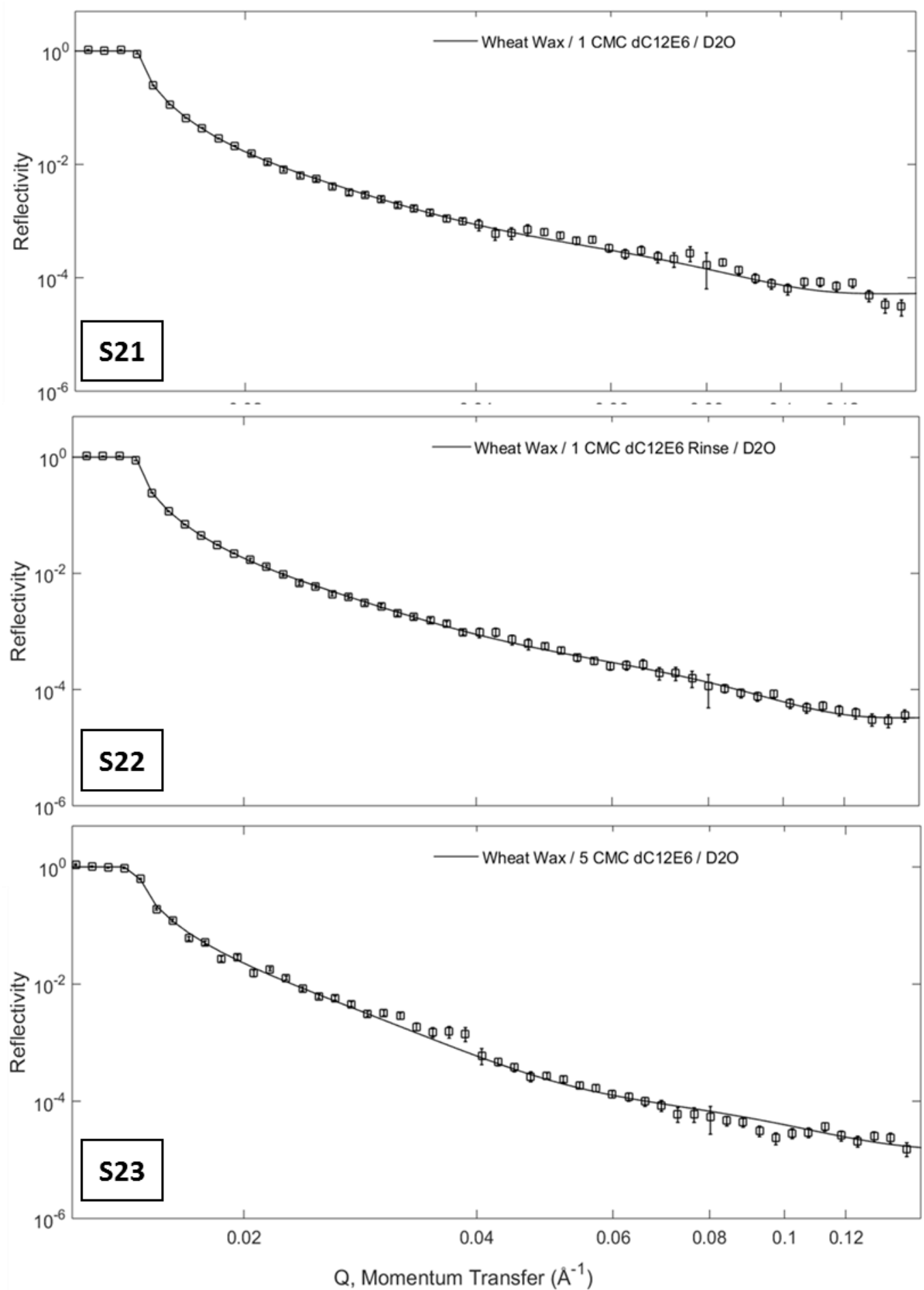

NR: Comparison of selected SLD and volume fraction profiles: 


\section{List of figures in section:}

Figure S24 SLD profiles of $\mathrm{hC}_{12} \mathrm{E}_{6} /$ wax interaction below CMC.

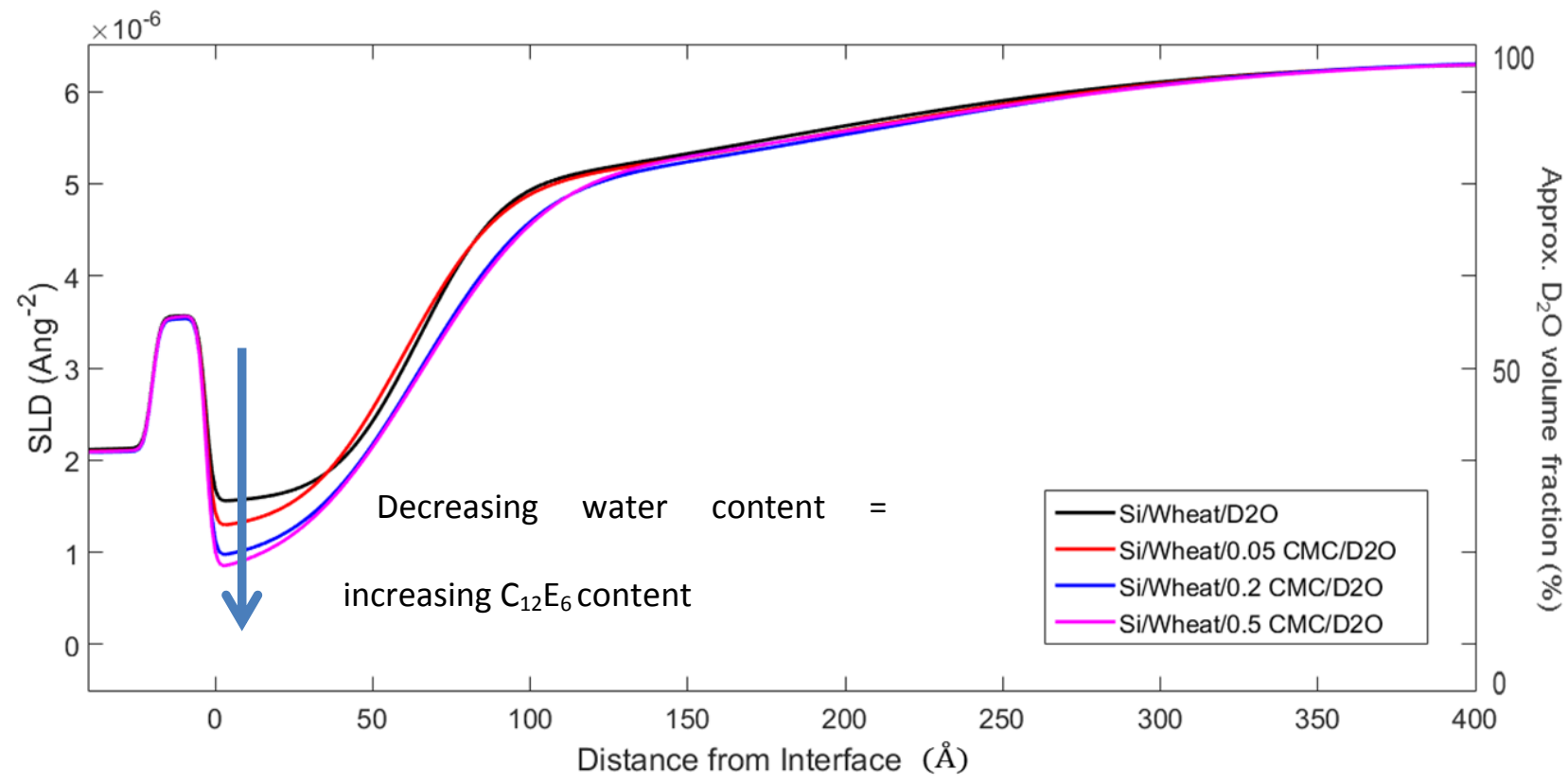

SLD profile and $\mathrm{D}_{2} \mathrm{O}$ volume fraction profile describing the distribution of the wax films at the interface below CMC. Figure compares the SLD of wheat wax film immersed in $\mathrm{D}_{2} \mathrm{O}$ to the profiles of measurements of wheat wax interacting with surfactant solutions $\left(\mathrm{hC}_{12} \mathrm{E}_{6}\right)$ at concentrations of 0.2 and $0.5 \mathrm{CMC}$. The wax reflectivity profiles are modelled using a 2-layer decay parameter model. Si/Wheat/0.2 CMC/D $2 \mathrm{O} \& \mathrm{Si} /$ Wheat/0.5 CMC/ $\mathrm{D}_{2} \mathrm{O}$ overlap.

Figure S25. NR profiles of $\mathrm{hC}_{12} \mathrm{E}_{6} /$ wax interaction - comparison of NR profiles determined for 0.5 CMC and 0.5 CMC-post-rinsing. While profiles appear identical at first view, due to 
precision of measurements, intricate variations at low $\mathrm{Q}$ result in the different structural parameters described in Table S3.

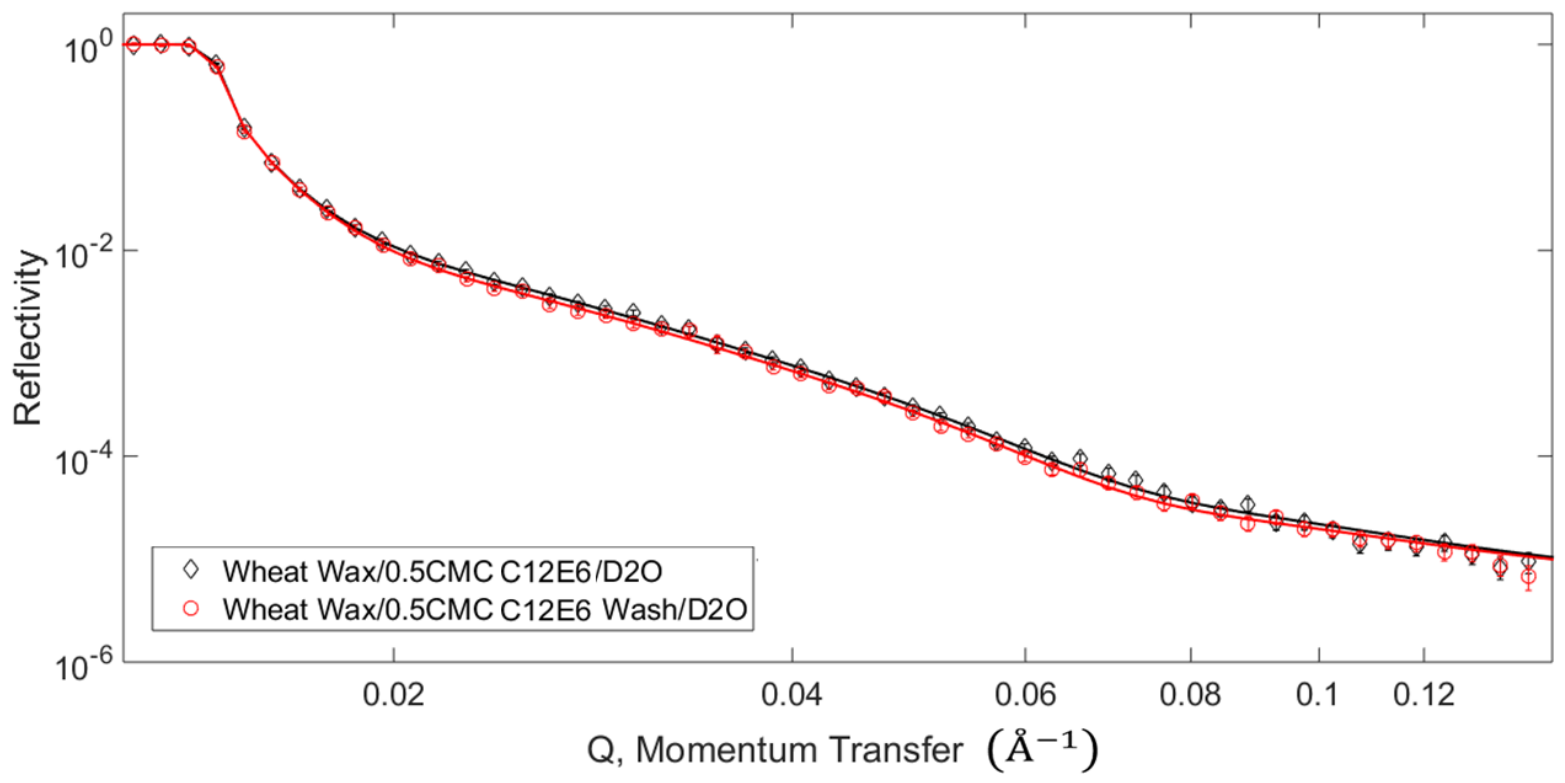

Figure S26. NR profiles of $h-\mathrm{C}_{12} \mathrm{E}_{6} /$ wax interaction - comparison of NR profiles determined for $5 \mathrm{CMC}$ and $5 \mathrm{CMC}$ post water-rinsing. Profile shows wax film undergoing major structural changes as described in the manuscript.

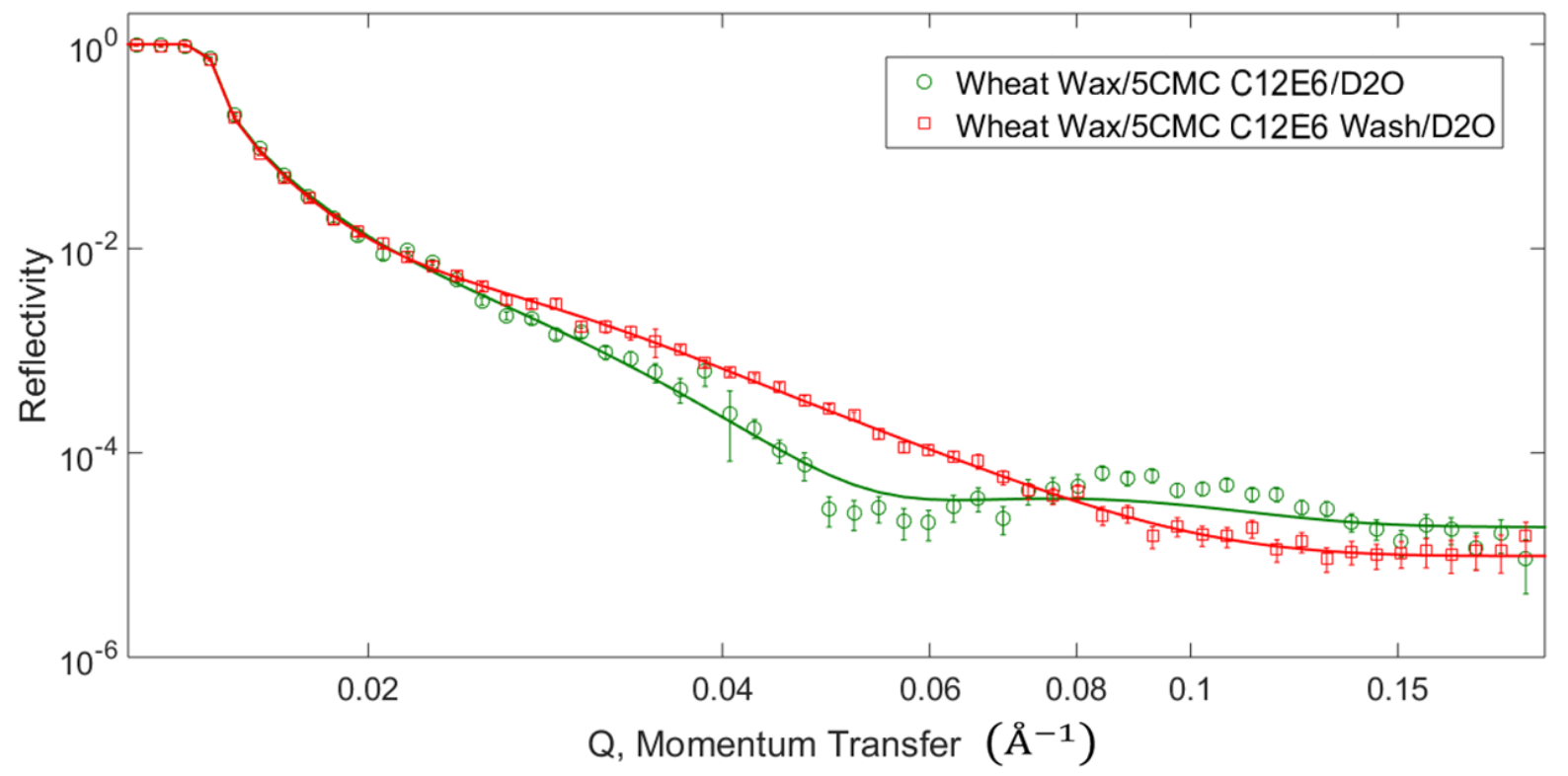

Figure S27. SLD profiles of $\mathrm{hC}_{12} \mathrm{E}_{6} /$ wax interaction - comparison of SLD profiles determined for wheat measured in $\mathrm{D}_{2} \mathrm{O}, 0.5 \mathrm{CMC}, 1 \mathrm{CMC}$ and 5 CMC-post-rinsing. 


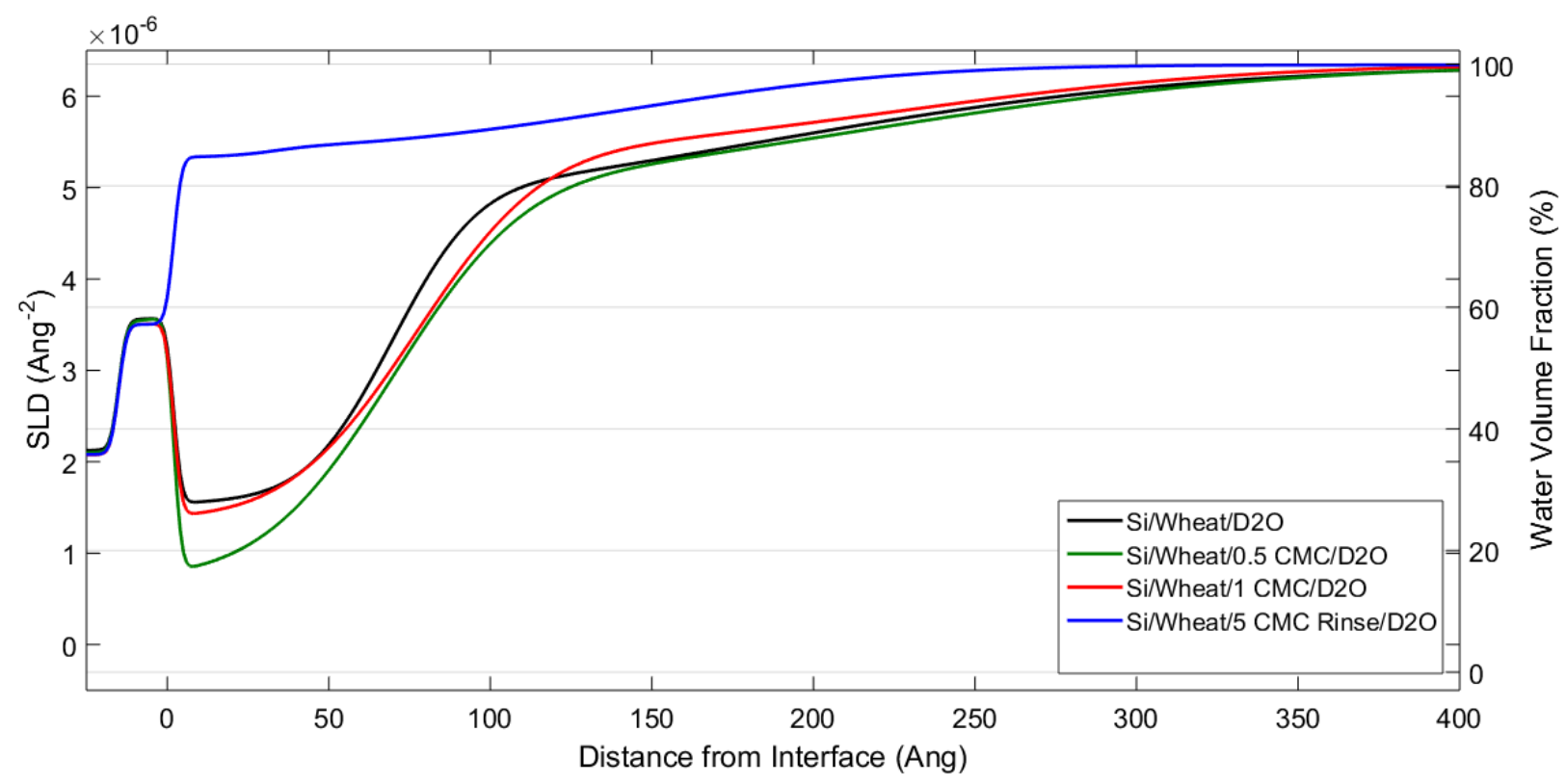

The associated SLD and water volume fraction profiles describe the distribution of the wax films at the interface. This figure compares the SLD of wheat wax film immersed in $\mathrm{D}_{2} \mathrm{O}$ to the profiles of measurements of wheat wax interacting with surfactant solutions $\left(\mathrm{hC}_{12} \mathrm{E}_{6}\right)$ at concentrations of $0.5,1$ and 5 CMC-post-rinsing. The wax reflectivity profiles are modelled using a 2-layer decay parameter model.

Figure S28. SLD profiles of $\mathrm{hC}_{12} \mathrm{E}_{6} /$ wax interaction - comparison of SLD profiles for the full set of measurement carried out below CMC 


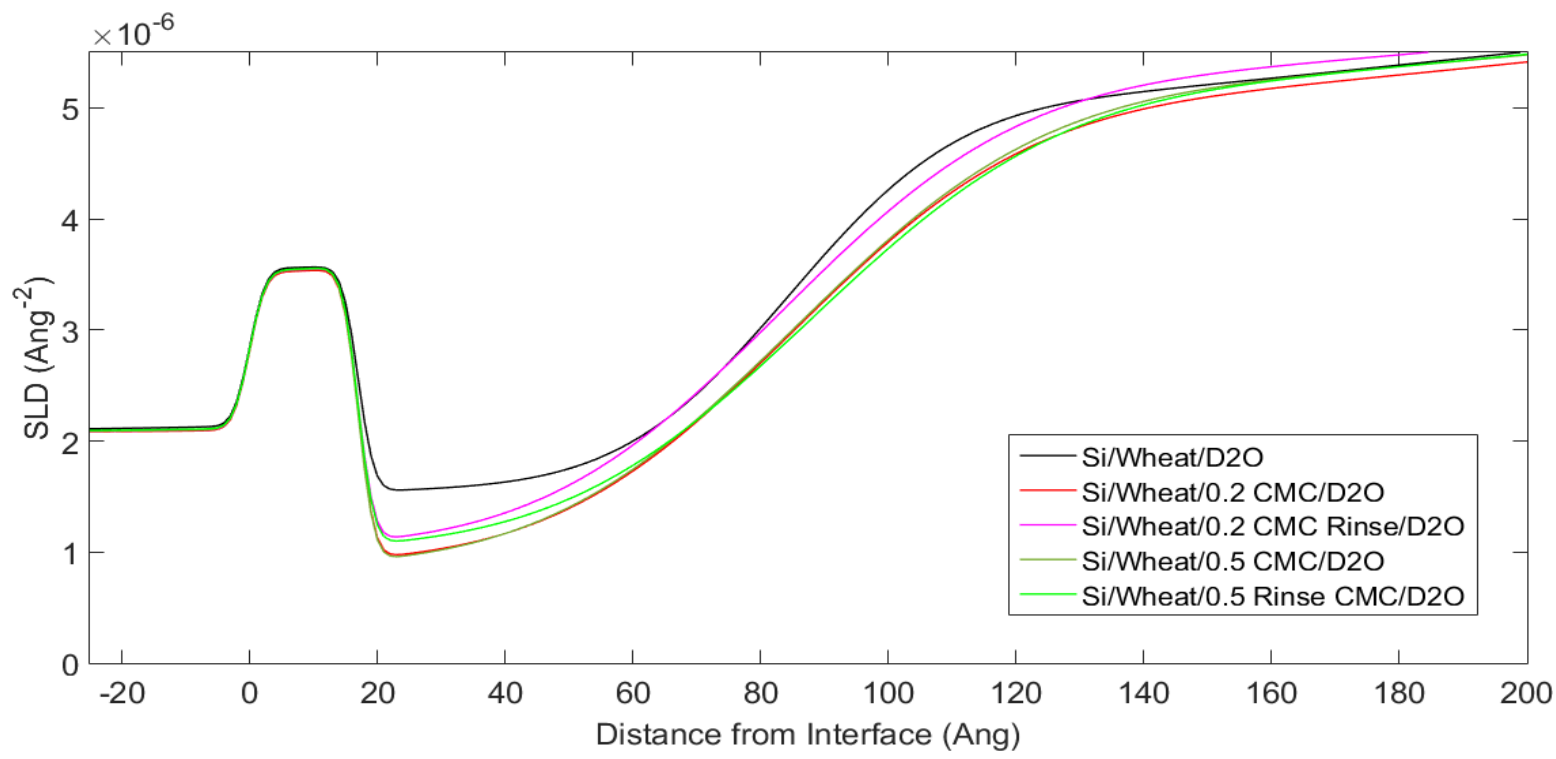

Reflectivity plots for reconstituted wheat wax films (normalised reflectivity vs momentum transfer, $Q$ ). Measurements were carried out under $\mathrm{D}_{2} \mathrm{O}$. This figure compares the reflectivity of a wheat wax film immersed in $\mathrm{D}_{2} \mathrm{O}$ to the profiles of measurements of wheat wax interacting with surfactant solutions $\left(\mathrm{hC}_{12} \mathrm{E}_{6}\right)$ at concentrations of $0.05,0.2$ and $0.5 \mathrm{CMC}$, as well as measurements of the wheat wax film after removing the introduced surfactant solutions and replacing them with $\mathrm{D}_{2} \mathrm{O}$ to observe the recovery of the wax film (increase in SLD corresponding to surfactant removal) after water rinsing of the surfactants. Error bars are smaller than symbols. The corresponding best-fitted structural parameters to the reflectivity plots are shown in Table S3.

Figure S29. NR profiles of $\mathrm{hC}_{12} \mathrm{E}_{6} /$ wax interaction - comparison of NR profiles of wax film measured under low concentration surfactant solutions to wax measured in $\mathrm{D}_{2} \mathrm{O}$. 


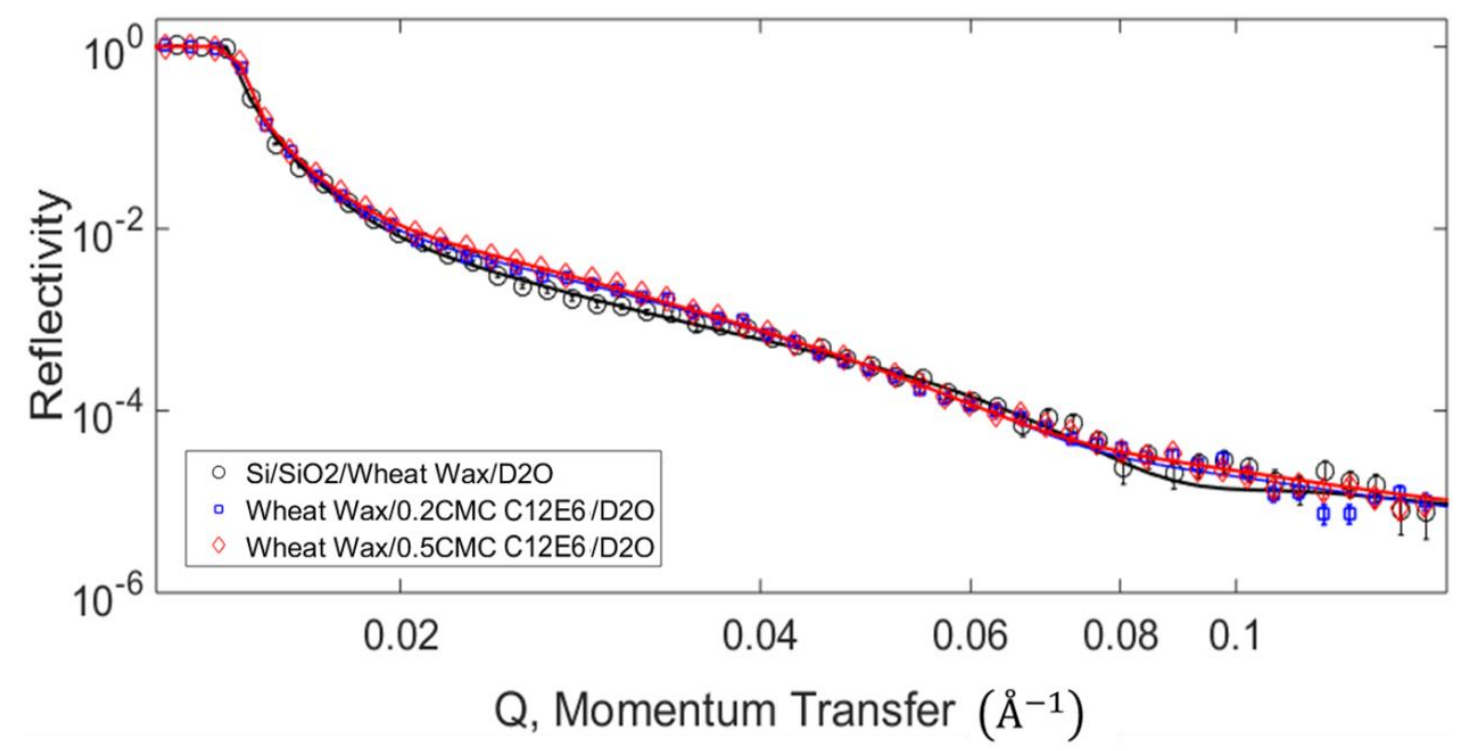

\section{References}

[S1] Koch, K.; Barthlott, W.; Koch, S.; Hommes, A.; Wandelt, K.; Mamdouh, W.; De-Feyter, S.; Broekmann, P. Structural Analysis of Wheat Wax (Triticum Aestivum, c.v. 'Naturastar' L.): From the Molecular Level to Three Dimensional Crystals, Planta. 2006, 223(2), 258-270.

[S2] Pambou, E.; Li, Z.; Campana, M.; Hughes, A.; Clifton, L.; Gutfreund, P.; Foundling, J.; Bell, G.; Lu, J. R. Structural Features of Reconstituted Wheat Wax Films. J. R. Soc. Interface. 2016, 13(120), 20160396.

[S3] Hughes, A. RasCal 1.1.3 (Neutron and X-ray Reflectivity Data Analysis Tool), ISIS Spallation Neutron Source, Rutherford Appleton Laboratory, [Software] 2014. 